\title{
Global Climate Simulated by the Seoul National University Atmosphere Model Version 0 with a Unified Convection Scheme (SAM0-UNICON)
}

\author{
Sungsu Park, JiHOon Shin, Siyun Kim, And Eunsil OH \\ School of Earth and Environmental Sciences, Seoul National University, Seoul, South Korea \\ YOONJAE KIM \\ Korea Meteorological Administration, Seoul, South Korea
}

(Manuscript received 19 November 2018, in final form 20 January 2019)

\begin{abstract}
As a contribution to phase 6 of the Coupled Model Intercomparison Project (CMIP6), the global climate simulated by an atmospheric general circulation model (GCM), the Seoul National University Atmosphere Model version 0 with a Unified Convection Scheme (SAM0-UNICON), is compared with observation and climates simulated by the Community Atmosphere Model version 5 (CAM5) and Community Earth System Model version 1 (CESM1), on which SAM0-UNICON is based. Both SAM0-UNICON and CESM1 successfully reproduce observed global warming after 1970. The global mean climate simulated by SAM0-UNICON is roughly similar to that of CAM5/CESM1. However, SAM0-UNICON improves the simulations of the double intertropical convergence zone, shortwave cloud forcing, near-surface air temperature, aerosol optical depth, sea ice fraction, and sea surface temperature (SST), but is slightly poorer for the simulation of tropical relative humidity, Pacific surface wind stress, and ocean rainfall. Two important biases in the simulated mean climate in both models are a set of horseshoe-shaped biases of SST, sea level pressure, precipitation, and cloud radiative forcings in the central equatorial Pacific and a higher sea ice fraction in the Arctic periphery and Southern Hemispheric circumpolar regions. Both SAM0UNICON and CESM1 simulate the observed El Niño-Southern Oscillation (ENSO) reasonably well. However, compared with CAM5/CESM1, SAM0-UNICON performs better in simulating the MaddenJulian oscillation (MJO), diurnal cycle of precipitation, and tropical cyclones. The aerosol indirect effect (AIE) simulated by SAM0-UNICON is similar to that from CAM5 but the magnitudes of the individual shortwave and longwave AIEs are substantially reduced.
\end{abstract}

\section{Introduction}

As a contribution to phase 6 of the Coupled Model Intercomparison Project (CMIP6), the most recent CMIP project, we summarize various aspects of the global climate simulated by the Seoul National University (SNU) Atmosphere Model version 0 with a Unified Convection Scheme (SAM0-UNICON) driven by the CMIP6 forcing data. SAM0-UNICON, one of the international general circulation models (GCMs) participating in CMIP6, is based on the Community Atmosphere Model version 5 (CAM5; Neale et al. 2010; Park et al. 2014). SAM0UNICON coupled with the identical land, ocean, and sea ice models of the Community Earth System Model version 1 (CESM1; Hurrell et al. 2013) will be referred to as Seoul National University Earth System Model

Corresponding author: Sungsu Park, sungsup@snu.ac.kr version 0 (SEM0). SAM0-UNICON (or SEM0) differs from CAM5 (or CESM1) in its treatment of atmospheric convection processes. More specifically, CAM5's shallow (Park and Bretherton 2009) and deep convection schemes (Zhang and McFarlane 1995; Neale et al. 2008; Richter and Rasch 2008) are replaced by the Unified Convection Scheme (UNICON; Park 2014a,b), and the treatment of the convective detrainment process in the CAM5 cloud macrophysics scheme (Park et al. 2014) is modified (Park et al. 2017). UNICON is a processbased model of subgrid convective plumes and mesoscale organized flow that does not rely on any equilibrium assumptions, such as convective available potential energy (CAPE) closure used in CAM5's deep convection scheme or convective inhibition (CIN) closure used in CAM5's shallow convection scheme and simulates all dry-moist, forced-free, and shallow-deep convection within a single framework in a seamless, consistent, and 
TABLE 1. Main components of atmospheric physics parameterizations and dynamic core used in SAM0-UNICON and CAM5. The schemes are listed in the order of time-splitting as explained in Park et al. (2014). Here, "PBL" denotes a planetary boundary layer scheme or equivalently, subgrid vertical transport scheme by local symmetric turbulent eddies; "convection" is a subgrid vertical transport scheme by nonlocal asymmetric turbulent eddies; "cloud macrophysics" computes cloud fraction, cloud overlap, and net condensation rate of water vapor into cloud liquid condensate; "stratus microphysics" computes the production and evaporation rates of stratiform precipitation (note that the production and evaporation rates of convective precipitation is computed in the convection scheme); and "aerosol" is a conversion scheme among various aerosol species. See the text for more details.

\begin{tabular}{lll}
\hline \hline \multicolumn{1}{c}{ Components } & \multicolumn{1}{c}{ SAM0-UNICON } & \multicolumn{1}{c}{ CAM5 } \\
\hline Deep convection & Park (2014a,b) & Zhang and McFarlane (1995) \\
Shallow convection & Park (2014a,b) & Park and Bretherton (2009) \\
Cloud macrophysics & Park et al. (2017, 2014) & Park et al. (2014) \\
Stratus microphysics & Morrison and Gettelman (2008) & Same \\
Radiation & Iacono et al. (2008), Pincus et al. (2003) & Same \\
Aerosol & Liu et al. (2012) & Same \\
PBL & Bretherton and Park (2009) & Same \\
Advection & Lin and Rood (1996) & Same \\
\hline
\end{tabular}

unified way (Park 2014a). It has been shown that UNICON successfully simulates various transitional phenomena associated with convection (e.g., the diurnal cycle of precipitation and the Madden-Julian oscillation (MJO; Madden and Julian 1971) without degrading the mean climate (Park 2014b; Yoo et al. 2015; Ahn et al. 2019). This improvement is mainly due to the explicit parameterization of complex interactions among convective updrafts, convective downdrafts, and mesoscale organized flow driven by subgrid cold pools, and associated simulation of convective plume memory across the time step, which cannot be simulated by CAM5's shallow and deep convection schemes (Park 2014a). Following Tiedtke (1993) and Teixeira and Kim (2008), the revised cloud macrophysics scheme (Park et al. 2017) diagnoses additional detrained cumulus that are not overlapped horizontally with cumulus and stratus clouds in each grid layer, by assuming a steady state balance between the detrainment rate of cumulus condensates and the dissipation rate of detrained condensates by entrainment mixing. The addition of detrained cumulus substantially improves the simulation of low-level clouds and the associated shortwave cloud radiative forcing, particularly in the subtropical trade cumulus regime (Park et al. 2017). Table 1 summarizes various atmospheric physics parameterizations and the dynamic core used in SAM0UNICON and CAM5.

The structure of this study is as follows. Section 2 provides a more detailed description of the structure of SAM0-UNICON and the simulation settings with CMIP6 forcing data. Section 3 summarizes various aspects of the mean climate and variabilities simulated by SAM0-UNICON, which are compared with those of CAM5/CESM1 and observations. It will be shown that the global mean climate simulated by SAM0-UNICON is roughly similar to that simulated by CAM5/CESM1. However, SAM0-UNICON substantially improves the simulations of the diurnal cycle of precipitation over land, MJO, and tropical cyclones with a reasonable simulation of El Niño-Southern Oscillation (ENSO). A summary and conclusion is provided in section 4 .

\section{Model description and simulation setting}

Similar to CAM5, SAM0-UNICON uses a time-split configuration, that is, in each time step, successive physics parameterizations and the dynamic core in the atmospheric model operate on the updated state resulting from the previous parameterization in the following order [see Fig. 1 of Park et al. (2014)]:

- a unified convection scheme (UNICON; Park 2014a,b) that computes grid-mean tendencies of $T$ (temperature); $q_{v}$ (water vapor); $u, v$ (horizontal momentum); and the mass and number concentrations of stratus liquid droplets $\left(q_{l}, n_{l}\right)$, stratus ice crystals $\left(q_{i}, n_{i}\right)$, and various aerosol species $\left(\xi_{m}, \xi_{n}\right)$, which are driven by subgrid vertical transport by nonlocal asymmetric turbulent eddies and mesoscale organized flow in association with subgrid cold pools [we note that UNICON also computes the cumulus fraction $\left(a_{c}\right)$ and the production and evaporation rates of convective precipitation in a diagnostic way within each grid layer using a single moment bulk cloud microphysics scheme];

- a stratiform macrophysics scheme (Park et al. 2014; Zhang et al. 2003) that computes the stratus fraction $\left(a_{s}\right)$ in a diagnostic way as the maximum of the liquid stratus fraction $\left(a_{l, s}\right)$ and ice stratus fraction $\left(a_{i, s}\right)$ with the addition of the detrained cumulus fraction $\left(a_{\mathrm{dc}}\right)$, that is, $a_{s}=\max \left(a_{l, s}, a_{i, s}\right)+a_{\mathrm{dc}}$; grid-mean net condensation rate of $q_{v}$ into $q_{l}\left(Q_{l}\right)$ using a saturation equilibrium constraint; and the associated decrease of $n_{l}$ when net evaporation occurs; 
- an aerosol activation (Abdul-Razzak and Ghan 2000) and ice nucleation (Liu and Penner 2005) scheme that computes the amount of aerosols activated into the cloud condensation nuclei (CCN) of stratus liquid droplets and ice nuclei (IN) of stratus ice crystals driven by local symmetric turbulent eddies and associated subrgid vertical transports of $\xi_{m}, \xi_{n}$, and $n_{l}$;

- a double-moment stratiform microphysics scheme (Morrison and Gettelman 2008) that computes $Q_{i}$ (grid-mean net sublimation rate of $q_{v}$ into $q_{i}$ by assuming that $q_{v}$ is deposited into $q_{i}$ only after $q_{l}$ is completely converted into $q_{i}$ by the Bergeron-Findensen process) and the production and evaporation rates of stratiform precipitation through 23 microphysical processes, in which $q_{l}, q_{i}, n_{l}, n_{i}$ are treated in a prognostic way but those of rain and snow droplets $\left(q_{r}, q_{s}, n_{r}, n_{s}\right)$ are treated in a diagnostic way without storage;

- an aerosol wet deposition scheme that computes the scavenging rate of cloud-borne and interstitial aerosols by convective and stratiform precipitations and the resuspension rate of aerosols by the evaporation of convective and stratiform precipitations;

- a subcolumn-based radiation scheme (Pincus et al. 2003; Iacono et al. 2008) that computes the grid-mean longwave (LW) and shortwave (SW) radiative heating rates using a single cloud type (i.e., a sum of $a_{s}$ and $a_{c}$ ) by assuming that $T$ and $q_{v}$ are homogeneous in each grid layer with an ice optics from Mitchell (2002);

- a surface flux scheme that computes the subgrid vertical transport of $T, q_{v}, u, v, \xi_{m}$, and $\xi_{n}$ at the ocean, land, and sea ice surfaces, respectively, using a MoninObukhov surface-layer similarity theory (Monin and Obukhov 1954);

- an aerosol conversion scheme (Liu et al. 2012) that computes the conversions among various aerosol species with three size categories (i.e., Aitken, accumulation, and coarse modes) and an atmospheric chemistry model;

- a planetary boundary layer (PBL) scheme (Bretherton and Park 2009) that computes the subgrid vertical transport of adiabatically conserved dry static energy $(s), q_{v}, u, v, q_{l}, q_{i}$, and $n_{i}$ by local symmetric turbulent eddies within the atmosphere (at this stage, the surface fluxes of $T, q_{v}, u, v, \xi_{m}$, and $\xi_{n}$ computed previously in the surface flux scheme are added into the atmospheric column) and a turbulent mountain stress (TMS) parameterization that computes the surface drag forces on $u, v$ of the lowest model layer caused by the subgrid variations of mountains;

- an aerosol dry deposition scheme (Zhang et al. 2001); and

- a finite volume (FV) dynamic core (Lin and Rood 1996, 1997) that computes three-dimensional advection of adiabatically conserved grid-mean potential temperature $(\theta), u, v, q_{v}, q_{l}, q_{i}, n_{l}, n_{i}, \xi_{m}, \xi_{n}$, and five additional variables associated with the subgrid mesoscale convective organization generated by UNICON.

Because UNICON is a diagnostic convection scheme, any scalars within the cumulus is not a part of the prognosed grid-mean thermodynamic scalars. To save computation time, stratus-borne aerosols (i.e., the aerosols within the stratus liquid droplets and ice crystals) are not advected by the advection scheme and interstitial aerosols (i.e., nonactivated aerosols) outside of $a_{c}$ are assumed to be horizontally homogeneous within each grid layer. Most diagnostic outputs are written at the beginning of the radiation scheme. Note that the subgrid vertical transports of $\xi_{m}, \xi_{n}$, and $n_{l}$ by local symmetric turbulent eddies are not treated within the PBL scheme but are treated in the aerosol activation routine. The ocean, land, and sea ice models are identical to those in CESM1.

All GCMs participating in CMIP6 are required to submit five mandatory simulations, the so-called Diagnostic, Evaluation and Characterization of Klima (DECK) experiments (Eyring et al. 2016). These include a preindustrial coupled simulation in the 1850 year at least for 500 years, a coupled simulation forced by an abrupt four time increase of global $\mathrm{CO}_{2}$ concentration from the equilibrated preindustrial coupled simulation for 150 years, a coupled simulation forced by a gradual increase of $\mathrm{CO}_{2}$ concentration at the rate of $1 \% \mathrm{yr}^{-1}$ from the equilibrated preindustrial coupled simulation for 150 years, a historical coupled simulation for 165 years from January 1850 to December 2014, and an Atmospheric Model Intercomparison Project (AMIP) simulation for 36 years from January 1979 to December 2014. According to the CMIP6 experiments specification, the simulations presented in our study are not Earth system model (ESM) simulations since the atmospheric $\mathrm{CO}_{2}$ concentration is prescribed instead of being calculated from the $\mathrm{CO}_{2}$ fluxes at the surface. We ran the five DECK simulations using SAM0UNICON and CAM5/CESM1, respectively, with the following configurations: the model physics time step $\Delta t=1800 \mathrm{~s}$, radiation time step $\Delta t=3600 \mathrm{~s}$, and dynamic subtime step $\Delta t=225 \mathrm{~s}$; horizontal resolution of $0.95^{\circ}$ latitude (lat) $\times 1.25^{\circ}$ longitude (lon) (also $0.475^{\circ}$ lat $\times 0.625^{\circ}$ lon for an additional AMIP simulation to produce more realistic tropical cyclones); 30 vertical layers with the midpoint height of the lowest model layer at the sigma pressure level of $\sigma=0.9926$, corresponding to $\sim 67 \mathrm{~m}$ over the ocean, and the highest model interface at $\sigma=0.00225$; and 60 vertical layers of the ocean model for the coupled simulations. Other than the use of the new CMIP6 forcing instead of the previous CMIP5 data, which will be described in the 
next paragraph, the detailed configurations of various coupled and AMIP simulations are identical to the ones described in appendix B of Park et al. (2014). All the parameter values used in our study are identical to those described in Park (2014b) and Park et al. (2017). Other than the parameters used in the convection scheme, SAM0-UNICON uses the same parameter values as those used in CAM5, except for the critical relative humidity for liquid stratus fraction $\left(\mathrm{RH}_{c, l}\right.$, a basic tuning parameter commonly used for achieving global radiation balance) that is tuned from 0.9 (CAM5) to 0.98 (SAM0-UNICON).

We summarize briefly how the CMIP6 forcing data described in Eyring et al. (2016) are processed and implemented into SAM0-UNICON and CAM5/CESM1:

- in the preindustrial coupled simulation, the prescribed global greenhouse gas (GHG) concentrations are held constant at $\mathrm{CO}_{2}=284.317 \mathrm{ppm}, \mathrm{CH}_{4}=808.249 \mathrm{ppb}$, and $\mathrm{N}_{2} \mathrm{O}=273.021 \mathrm{ppb}$, with other GHGs being treated with an equivalent radiative forcing of $32.118 \mathrm{ppt}$ of CFC11;

- in the AMIP and twentieth-century historical simulations, we used the transient time series of global annual-mean GHG concentrations;

- monthly ozone concentration is prescribed as a function of $(x, y, z)$ with a specified annual cycle;

- monthly spectral solar irradiance is set to $1 \mathrm{AU}$;

- for stratospheric aerosol forcing, we use the monthly zonal mean mass concentration for sulfuric acid, and the surface area density of stratospheric aerosol is calculated from the mass concentration;

- annual surface fluxes of $\mathrm{NO}_{x}$ and $\mathrm{NH}_{y}$ are used to compute nitrogen deposition forcing;

- the aerosol emission forcing from the CMIP6 data is processed following the AEROCOM protocol size distribution and injection height, with the specified emissions of $\mathrm{SO}_{2}, \mathrm{SO}_{4}$, black carbon, primary organic matter (equivalent to organic carbon in CMIP6 emission data), secondary organic aerosol (include alkanes, aromatics, and biogenic hydrocarbons), and dimethyl sulfide (equivalent to $\mathrm{C}_{2} \mathrm{H}_{6} \mathrm{~S}$ in the CMIP6 emission data); and

- for the land use forcing, we use the same land cover change data as the CMIP5, since the CESM1 land model uses its own land cover type categorization; however, the harvest area information is substituted with the CMIP6 forcing data.

\section{Results}

\section{a. Time series of global annual-mean surface temperature}

Figure 1a shows the time series of global annual-mean surface temperature (TS) from the preindustrial coupled

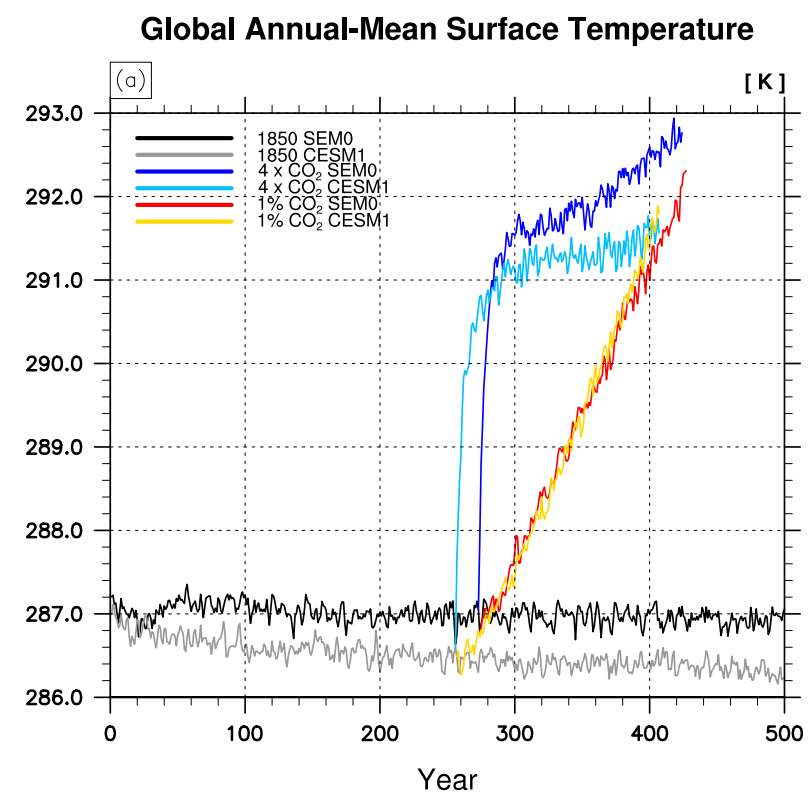

\section{Global Annual-Mean Surface Temperature}

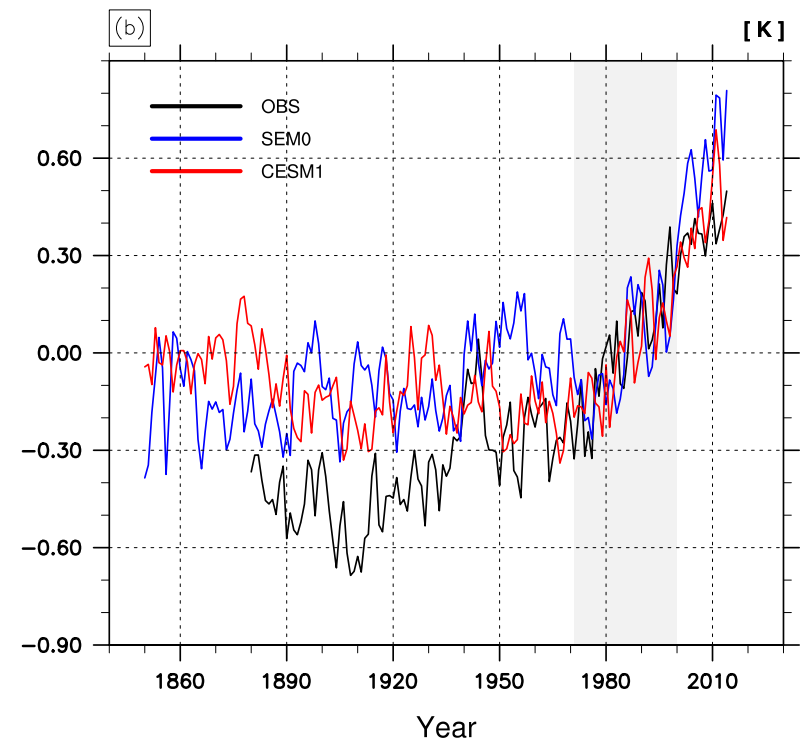

FIG. 1. Time series of global annual-mean TS from (a) the 1850 preindustrial coupled simulation for 500 years (black, gray), an instantaneous $4 \times \mathrm{CO}_{2}$ increase simulation for 150 years (purple, blue), a gradual $\mathrm{CO}_{2}$ increase simulation at the rate of $1 \% \mathrm{yr}^{-1}$ for 150 years (red, yellow), and (b) the twentieth-century historical simulations during January 1850 and December 2014 compared with the MLOST observations. All $4 \times \mathrm{CO}_{2}, 1 \% \mathrm{CO}_{2}$, and twentiethcentury simulations are branched from the 1850 preindustrial simulations at the year 274 for SEM0 and 257 for CESM1, respectively. In (b), the anomalies with respect to the temporal mean TS during January $1971-$ December $2000\left(14.0^{\circ} \mathrm{C}\right.$ for SEM0 and $13.4^{\circ} \mathrm{C}$ for CESM1) are shown. 
simulations and two experiments with the instantaneously quadrupled and gradually increasing global $\mathrm{CO}_{2}$ concentrations. After an initial shock during the first 50 years, the SEM0 preindustrial simulation approaches an equilibrium state but CESM1 suffers from a continuous cooling. The interannual standard deviations of the detrained global mean TS during the 200-500 years are $0.097^{\circ} \mathrm{C}$ for SEM0 and $0.086^{\circ} \mathrm{C}$ for CESM1. As soon as the $\mathrm{CO}_{2}$ concentration is quadrupled, global mean TS increases very rapidly and reaches an unstable equilibrium state after 50 years with the semiequilibrium TS about $4.7^{\circ}$ (SEM0) and $4.9^{\circ} \mathrm{C}$ (CESM1) warmer than the initial value. Instead of approaching a stable equilibrium state, the global mean TS increases further. When the $\mathrm{CO}_{2}$ concentration gradually increases by $1 \% \mathrm{yr}^{-1}$, the global mean TS increases almost linearly with time at the rate of $0.03^{\circ} \mathrm{Cyr}^{-1}$ (SEM0) and $0.037^{\circ} \mathrm{Cyr}^{-1}$ (CESM1). After 150 years, at which the $\mathrm{CO}_{2}$ concentrations from the quadrupled and gradually increasing experiments become identical, the global mean TS from these two $\mathrm{CO}_{2}$ experiments with CESM1 are roughly similar to each other, but SEM0 simulates a warmer climate for the quadrupled case than for the gradually increasing case.

Figure $1 \mathrm{~b}$ shows the anomalies of global mean TS with respect to the 30-yr average during 1971-2000 obtained from the twentieth-century coupled simulations and observations. The overall trend of global mean TS simulated by SEM0 is similar to that of CESM1; but the global mean TS averaged over 1971-2000 from SEM0 is about $0.6^{\circ} \mathrm{C}$ higher than that of CESM1. Similar to the observations, both SEM0 and CESM1 simulate a rapid increase of global mean TS after 1970 but the observed increasing trend from 1910 to 1940 is not evident in either simulation. With SEM0, we performed additional ensemble simulations for the twentieth-century and quadrupled $\mathrm{CO}_{2}$ concentration experiments by branching off at different years from the preindustrial coupled simulation. It is not shown here, but the analysis results from the other ensemble simulations were very similar to those from the default simulation shown in this study.

\section{b. Mean climate}

\section{1) Global AnNuAl-MEAn STAtistics}

Figure 2 is a Taylor diagram (Taylor 2001) summarizing the performance of the models in reproducing the observed global mean climate. The observation data used for this diagram are the ECMWF interim reanalysis product (ERAI; Simmons et al. 2007), the Clouds and Earth's Radiant Energy Systems Energy Balanced and Filled (CERES-EBAF; Loeb et al. 2009), the Global Precipitation Climatology Project (GPCP; Adler et al. 2003), the Willmott-Matsuura surface air temperature (Willmott; Willmott and Matsuura 1995), and the European Remote Sensing Satellite Scatterometer (ERS; Bentamy et al. 1999).

The overall performance of SAM0 and SEM0 to simulate the observed global mean climate is similar to CAM5 and CESM1. However, SAM0 slightly performs better than CAM5 (the RMSE of SAM0 versus the observations relative to that of CAM5 is 0.965) but SEM0 slightly performs worse than CESM1 (the RMSE of SEM0 relative to that of CESM1 is 1.034). CAM5's shallow and deep convection schemes compute convective updraft mass fluxes using certain equilibrium closures based on the CIN and CAPE, which prevent the simulated mean atmospheric state from deviating far from a certain equilibrium state. In contrast, the convection scheme used in SAM0 (a unified convection scheme, UNICON) is a process-based model that does not rely on any equilibrium constraints. As a result, a successful simulation of the observed mean climate with SAM0/SEM0 is as difficult as or more difficult than simulating the observed variability, requiring careful parameterizations for various convection processes and the feedback among them. Given this, it is quite encouraging that the mean climate simulated by SAM0/SEM0 is as good as CAM5/CESM1. A slight degradation of SAM0/ SEM0's RMSE score relative to CAM5/CESM1 from the uncoupled to coupled simulation reflects these contrasting characteristics of the convection schemes in the two models (i.e., process-based or equilibrium-closure based).

Both the uncoupled and coupled simulations show a distinct correlation barrier between the gridscale environmental variables (e.g., sea level pressure, land 2-m temperature, zonal wind at $300 \mathrm{hPa}$, and temperature) that have correlations with the observations higher than 0.95 and the other variables mostly associated with cloud and precipitation processes. This indicates that substantial portions of the insufficient model performance are associated with subgrid physics parameterizations. Compared to CAM5/CESM1, SAM0/CEM0 improves the simulations of shortwave cloud radiative forcing (SWCF) and land rainfall but slightly degrades the simulations of Pacific surface wind stress, relative humidity and ocean rainfall, particularly in the coupled simulations. In SAM0/SEM0, the coupling with the interactive ocean and sea ice fraction models tends to degrade the correlation statistics but suppresses the excessive spatiotemporal variability. The exception is the ocean rainfall, whose spatiotemporal variability is enhanced from SAM0 to SEM0.

\section{2) SEA LEVEL PRESSURE AND SURFACE WIND STRESS}

Figures 3 and 4 show the global climatology of sea level pressure (SLP) and surface wind stress from the 

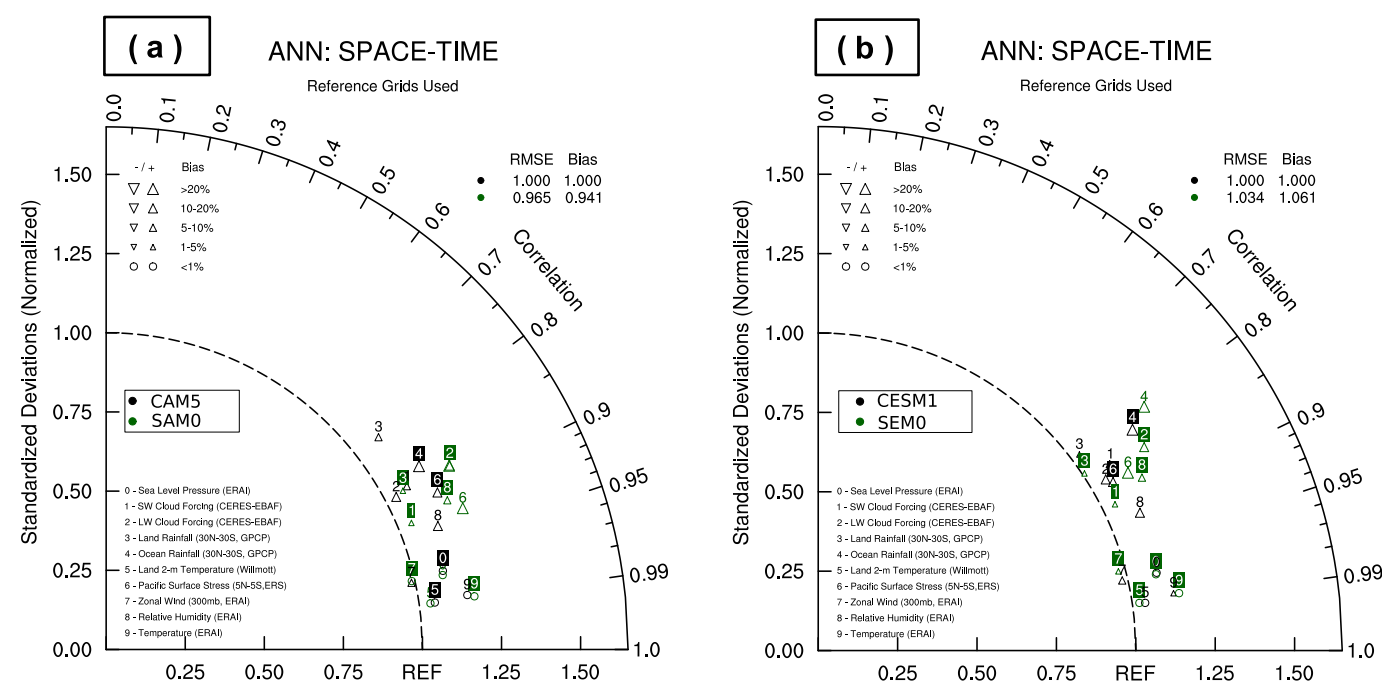

FIG. 2. A space-time Taylor diagram from the (a) AMIP and (b) twentieth-century historical simulations during January 1979-February 2014. The Taylor diagram shows the global performance of SAM0/SEM0 (green) relative to CAM5/CESM1 (black) vs the observations measured by the correlation and standardized deviation of 10 semiindependent climate variables indicated on the lower-left portion of the figure. For each variable, using the monthly climatology for all the available grid points, we compute the correlation with the observation and standardized deviation as the ratio of the simulated spatiotemporal standard deviation to the observed standard deviation, including the annual cycle. Any variable with a correlation of 1 and a standardized deviation of 1 indicates a perfect simulation of that variable. The RMSE $=0.965$ (1.034) of SAM0 (SEM0) is the average of the relative RMSE of a simulated individual variable vs the observation with respect to the RMSE of CAM5 (CESM1), that is, $\operatorname{RMSE}(\mathrm{SAM} 0)=(1 / 10) \sum_{i=0}^{9}\left[\operatorname{RMSE}_{i}(\mathrm{SAM} 0) / \operatorname{RMSE}_{i}(\mathrm{CAM} 5)\right]$, where $i$ is a variable index. The Bias $=0.941$ (1.061) of SAM0 (SEM0) is the average of the relative annual mean of an individual variable with respect to CAM5 $(\mathrm{CESM} 1)$, that is, $\operatorname{Bias}(\mathrm{SAM} 0)=(1 / 10) \sum_{i=0}^{9}\left[\operatorname{mean}_{i}(\mathrm{SAM} 0) / \operatorname{mean}_{i}(\mathrm{CAM})\right]$, where $\operatorname{mean}_{i}$ is a global annual mean of the $i$ th variable.

ERAI and ERS observations and the model biases compared to the observations during DJF and JJA, respectively. SLP is instrumental in controlling cloud and precipitation processes [e.g., SWCF, longwave cloud radiative forcing (LWCF), surface precipitation rate (PRECT)] and the biases of other environmental variables (e.g., wind, temperature, humidity), such that a careful analysis of SLP biases is a first step in understanding model behavior. All simulations produce negative SLP biases in the tropical Pacific and Indian Oceans, which are particularly strong during DJF and are amplified from the uncoupled to coupled simulations. Also simulated are the zonally symmetric positive SLP biases along $45^{\circ}-50^{\circ} \mathrm{S}$ and negative biases along $70^{\circ} \mathrm{S}$ and farther poleward during DJF, which are slightly alleviated by the coupling and changed into a wave pattern during JJA. Strong positive SLP biases over the Arctic, North Pacific, and North Atlantic Oceans during JJA are substantially reduced from CAM5/CESM1 to SAM0/SEM0, although they are still persisting. Also notable are the negative SLP biases over Asia, South America, and the United States during summer, which tend to be alleviated by the coupling. During DJF, SEM0 (also CESM1) suffers from strong negative SLP biases over the Arctic and an anomalous north-south SLP dipole over the North Atlantic Ocean extending into nearby Europe, North America, northern Africa, and Saudi Arabia. These SLP biases are closely associated with the biases in the other climate variables as will be discussed. A comparison of the RMSE of SLP indicates that SAM0/ SEM0 performs better than CAM5/CESM1 during JJA, while CESM1 does better than SEM0 during DJF.

The biases of surface wind stress are closely tied to the SLP biases. During DJF, strong positive biases of surface wind stress over the far North Atlantic Ocean are associated with the anomalous SLP dipole there. The zonally elongated positive biases of surface wind stress along $30^{\circ}$ and $60^{\circ} \mathrm{S}$ during DJF are also associated with the zonally symmetric positive SLP biases along $45^{\circ}-$ $50^{\circ} \mathrm{S}$. Over the North Pacific and Atlantic Oceans during JJA, both models produce anticyclonic anomalies of surface wind in association with anomalous high SLP. Although weaker than the ones in the midlatitudes, the biases of surface wind stress in the tropical regions can exert substantial impacts on the global climate through complex feedback and teleconnection processes. In the central equatorial Pacific region denoted by the green 
Sea Level Pressure DJF OBS (ERAI)
Surface Wind Stress DJF

OBS (ERS)
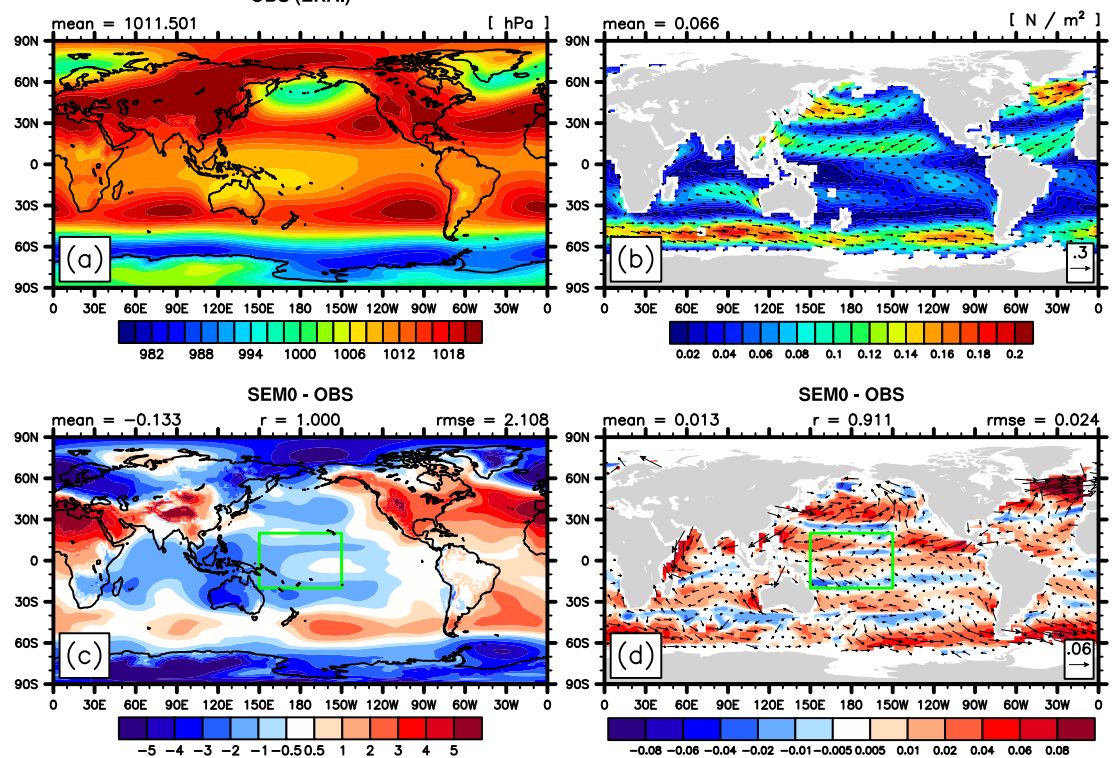

CESM1 - OBS

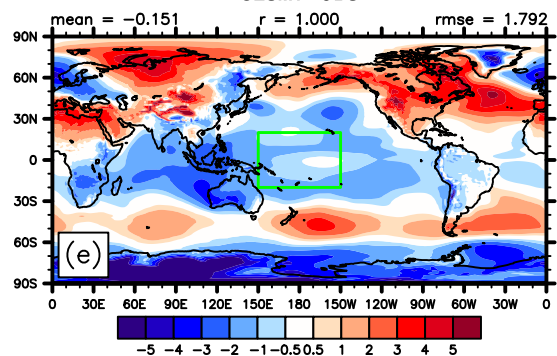

SAMO - OBS

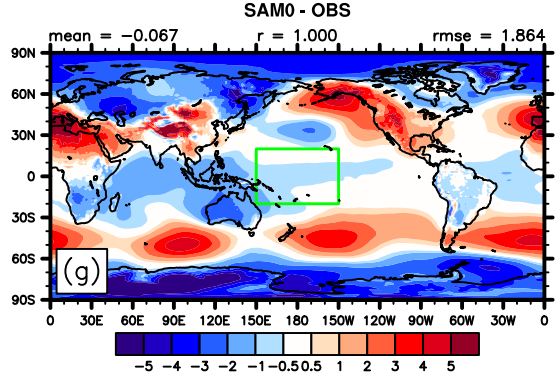

CAM5 - OBS

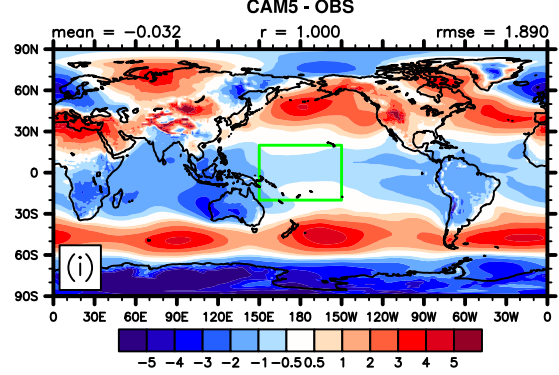

SEMO - OBS

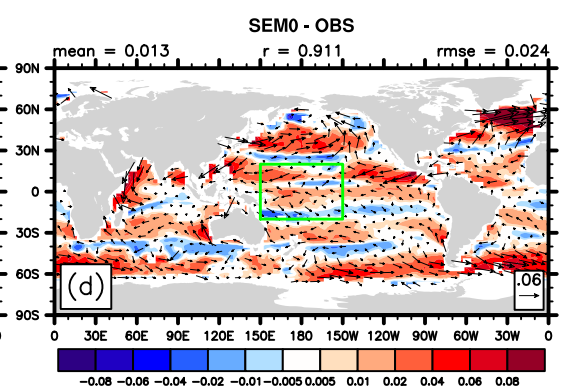

CESM1 - OBS

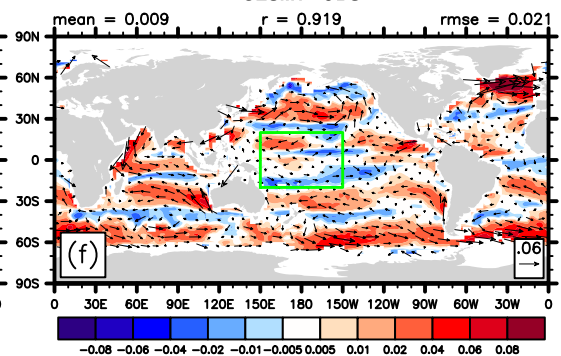

SAMO - OBS

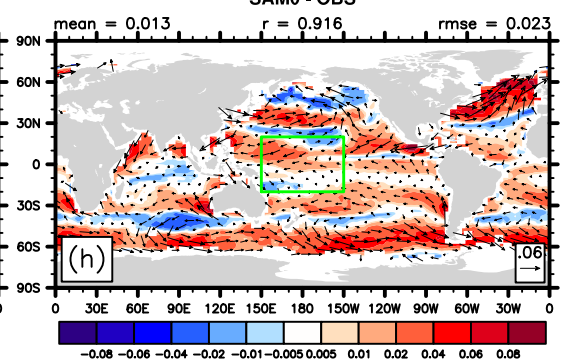

CAM5 - OBS

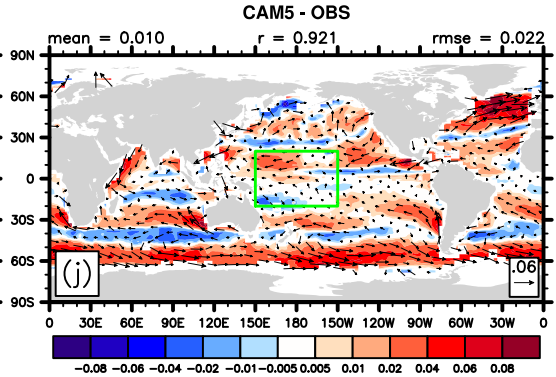

FIG. 3. DJF climatologies of (a) SLP from the ERAI during January 1989-December 2005 and (b) surface wind stress from the ERS scatterometer during January 1992December 2000, and the model biases compared to the observations from (c),(d) SEM0; (e),(f) CESM1; (g),(h) SAM0; and (i),(j) CAM5 during January 1979-December 2014. The following figures will use the same period of January 1979-December 2014 for plotting simulation results, unless specified otherwise. 
Sea Level Pressure JJA OBS (ERAI)
Surface Wind Stress JJA

OBS (ERS)

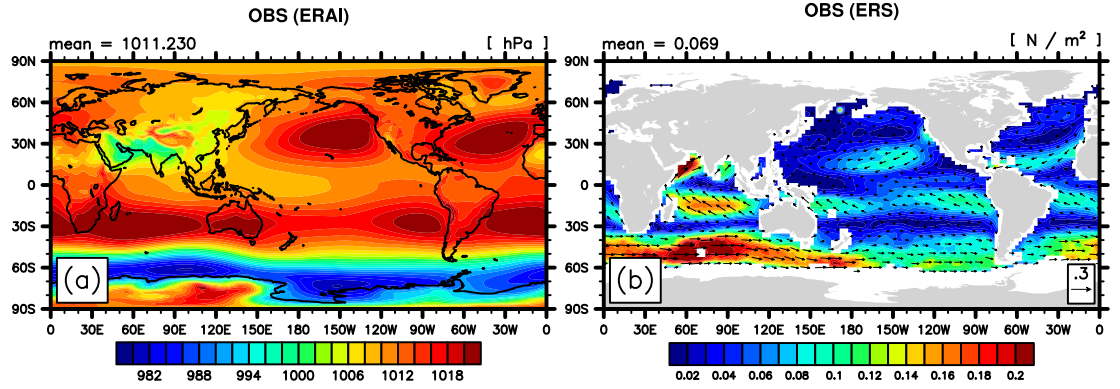

SEMO - OBS

SEMO - OBS
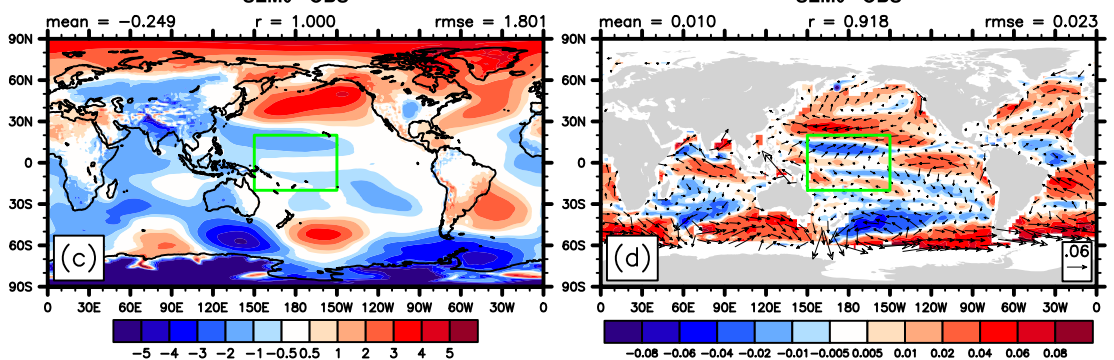

CESM1 - OBS

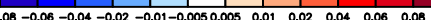

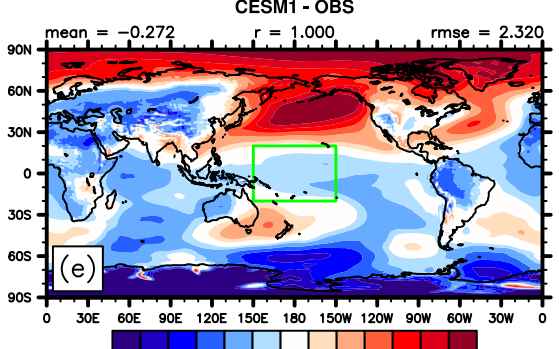

\begin{tabular}{llllllllllllll}
-5 & -4 & -3 & -2 & -1 & -0.50 .5 & 1 & 2 & & & & \\
\hline
\end{tabular}

SAMO - OBS
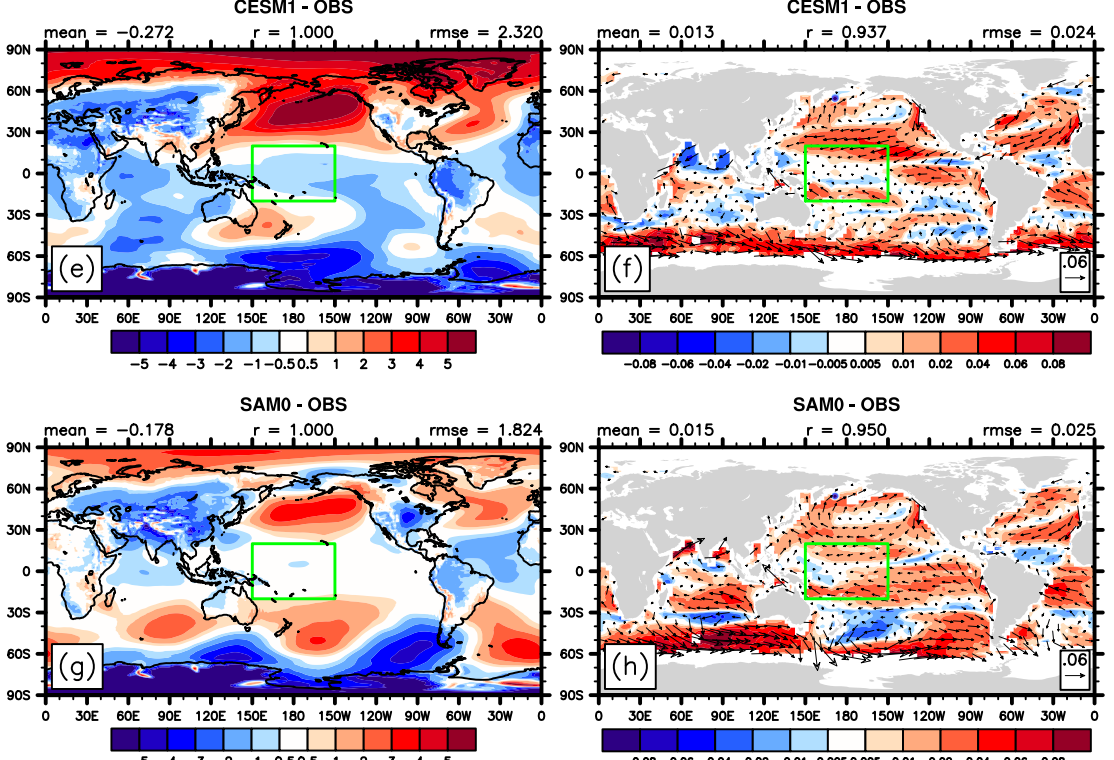

SAMO - OBS

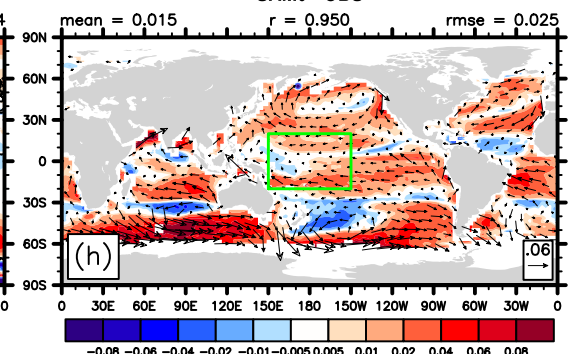

CAM5 - OBS

CAM5 - OBS

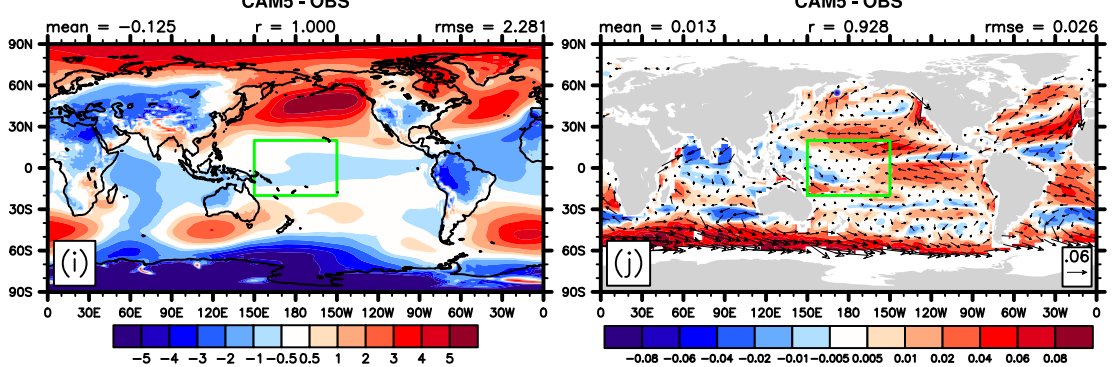

FIG. 4. As in Fig. 3, but during JJA. 
box, SEM0 simulates anomalous easterly and offequatorial divergent surface winds, which are consistent with the SLP bias pattern there. As will be shown later, these biases are closely associated with the biases of SWCF, LWCF, PRECT, and SST in this region. Given that the mean biases in many climate variables are tied to the SLP biases and successful simulations of various variabilities (e.g., MJO, synoptic storm track, atmospheric blocking, tropical cyclones, ENSO) are dependent on the successful simulation of the mean climate state, more intensive efforts are necessary to understand the sources of SLP and wind stress biases, as well as the continuous efforts to incorporate various new physical processes (i.e., clouds and aerosols) into the GCM.

\section{3) Precipitation Rate at the Surface AND PRECIPITATION SPECTRA}

Figure 5 shows the global climatology of PRECT during DJF and JJA from the GPCP observation and the model biases compared to the observations. All simulations produce higher global mean PRECT than the observations by $11 \%-15 \%$. SEM0 (SAM0) produces more (less) global mean PRECT than CESM1 (CAM5), and the global pattern correlation $r$ and RMSE simulated by SEM0 are worse than SAM0, implying that a certain set of coupling processes anomalously enhances and degrades the hydrological cycle in SEM0. Specifically, SEM0 simulates a too strong PRECT along the ITCZ and South Pacific convergence zone (SPCZ) that extends too far eastward but a too weak PRECT along the central equatorial Pacific Ocean surrounded by the ITCZ and SPCZ (see the green box area in the figure). This horseshoe-patterned anomalous PRECT, which also exists in CESM1 and tends to be strengthened by the coupling, is closely tied to the biases of SLP and surface wind stress: the positive SLP bias and divergent easterly surface wind along the equator where the simulated PRECT is too small and the opposite negative SLP bias and convergent surface wind in the surrounding off-equatorial areas where the simulated PRECT is too much. Similarly, the positive PRECT biases over the equatorial Indian Ocean and Australia during DJF and along the equatorial Atlantic Ocean during JJA are closely related with anomalous low SLP and convergent surface wind. Two notable improvements from CESM1 to SEM0 are the suppression of a spurious double ITCZ over the eastern equatorial Pacific and Atlantic Oceans during DJF and the reduction of strong negative biases in South America. Although weaker than the biases in the tropical regions, we also note the positive PRECT biases along the $35^{\circ} \mathrm{N} / \mathrm{S}$ during boreal winter, which contribute to the positive biases of global mean PRECT in all simulations.

Figure 6 shows the frequency (FQ) spectra of daily PRECT from the observations and simulations computed at two different horizontal resolutions. The raw TRMM satellite data (Huffman et al. 2007) provided every $3 \mathrm{~h}$ at the $0.25^{\circ}$ lat $\times 0.25^{\circ}$ lon horizontal resolution were averaged into the daily data at the same horizontal resolutions as the simulations being compared. At the $1^{\circ}$ lat $\times 1^{\circ}$ lon resolution, all simulations underestimate the observed frequency of very weak PRECT of less than $1 \mathrm{~mm} \mathrm{day}^{-1}$ but overestimate moderate PRECT between 1 and $20 \mathrm{~mm} \mathrm{day}^{-1}$ (Fig. 6a). For strong PRECT between 30 and $150 \mathrm{mmday}^{-1}$, SAM0/ SEM0 simulate more realistic precipitation frequency than do CAM5/CESM1, which substantially underestimate the observations. In the case of very strong PRECT of over $200 \mathrm{~mm} \mathrm{day}^{-1}$, most of which comes from convective precipitation in both models, CAM5/CESM1 (particularly, CESM1) perform better than SAM0/SEM0, which overestimate the observations. Coupling tends to slightly reduce the frequency of very strong PRECT in both models. As the horizontal resolution becomes finer, both the observations and models increase the frequency of strong and very strong PRECT (Fig. 6b). However, the models have stronger resolution sensitivity than the observations and generate a very strong PRECT too frequently at the $0.5^{\circ}$ lat $\times 0.5^{\circ}$ lon resolution. If the observation data are correct, without an arbitrary upper limit on the retrieved precipitation rate, this difference in resolution sensitivity of surface precipitation between the models and observations will provide an important clue for the future development of a scale-adaptive GCM that can operate at various horizontal resolutions without a resolution-dependent tuning exercise.

\section{4) Cloud Radiative FORCing}

Figure 7 shows the annual mean SWCF and LWCF at the top of the atmosphere from the CERES-EBAF observations and the model biases compared to the observation. Compared to CAM5/CESM1, SAM0/ SEM0 substantially improves the simulation of SWCF with the reduction of RMSE from 13.03/14.39 to 8.75/ $9.81 \mathrm{~W} \mathrm{~m}^{-2}$. These improvements are mainly from the reduction of strong negative bias over the tropical continents and positive bias over the subtropical marine trade cumulus regimes. The former is due to a smaller cumulus fraction (Park et al. 2014), while the latter is due to the diagnosis of an additional detrained cumulus fraction (Park et al. 2017). Also improved are the decreases of positive SWCF biases over the Arctic 
PRECT DJF

OBS (GPCP)

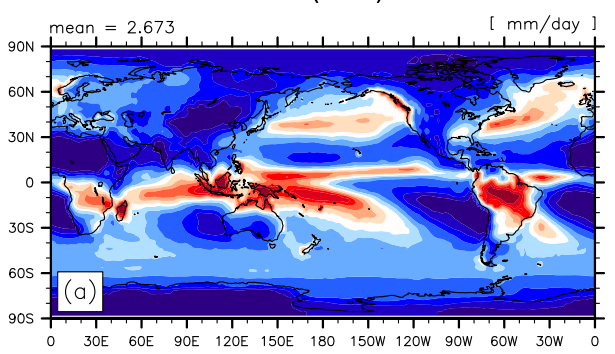

PRECT JJA

OBS (GPCP)

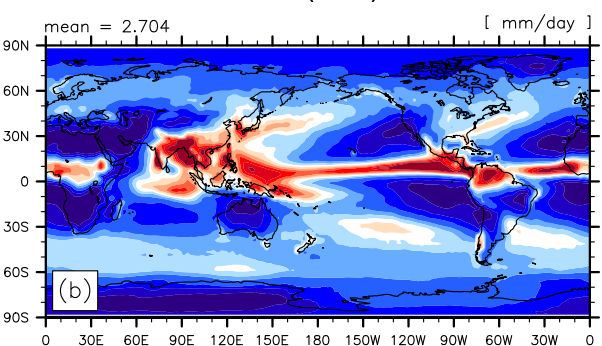

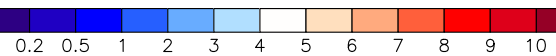
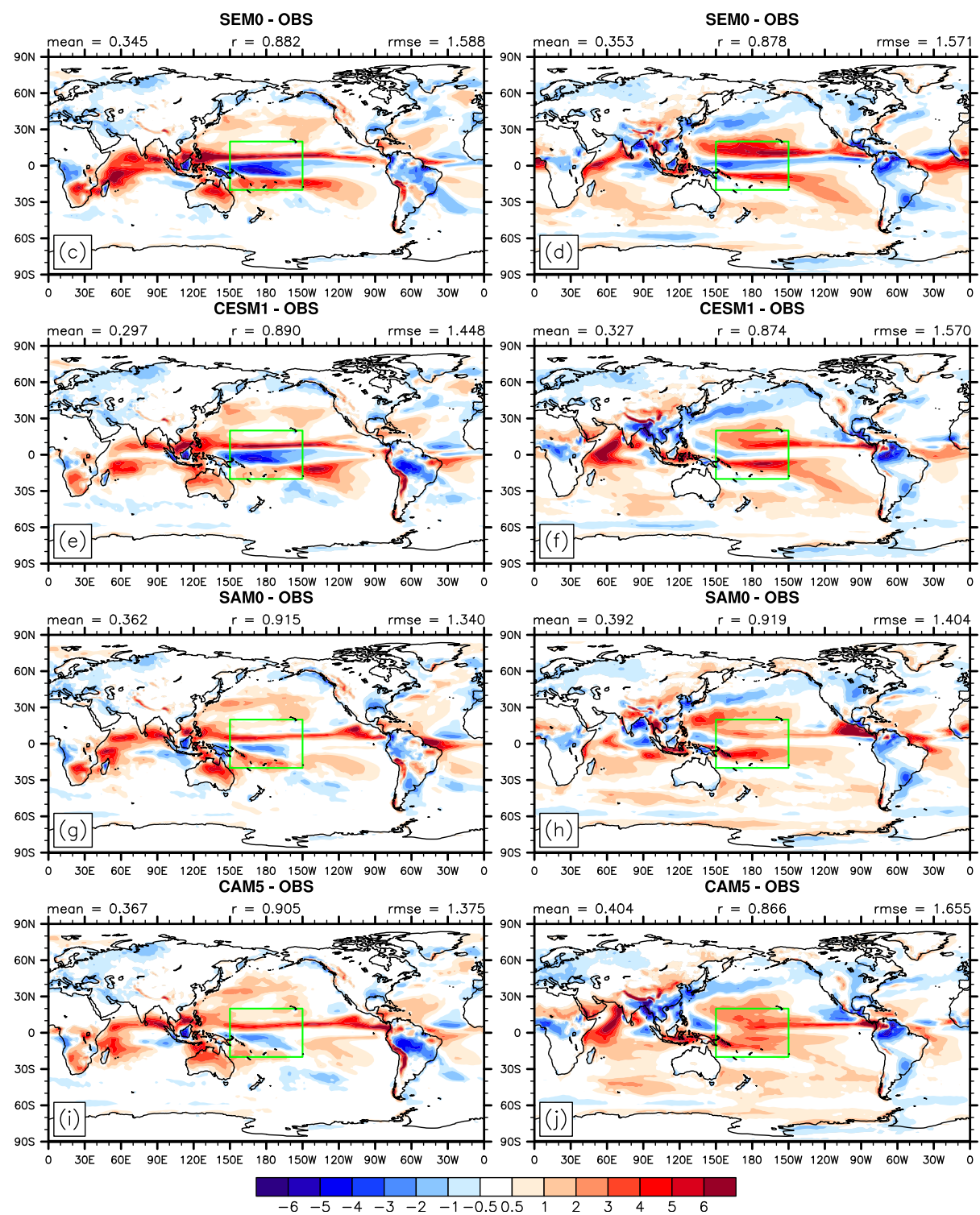

FIG. 5. Total (convective plus stratiform) precipitation rate at the surface (PRECT) in (left) DJF and (right) JJA from (a),(b) the GPCP observation during January 1979-December 2009, and the biases compared to the observations from (c),(d) SEM0; (e),(f) CESM1; (g),(h) SAM0; and (i),(j) CAM5. The global-mean value is shown at the top left of each plot. The pattern correlation and RMSE between the simulation and the observation are shown at the top center and the top right of an individual simulation plot, respectively. A similar convention will be applied to the following figures. 

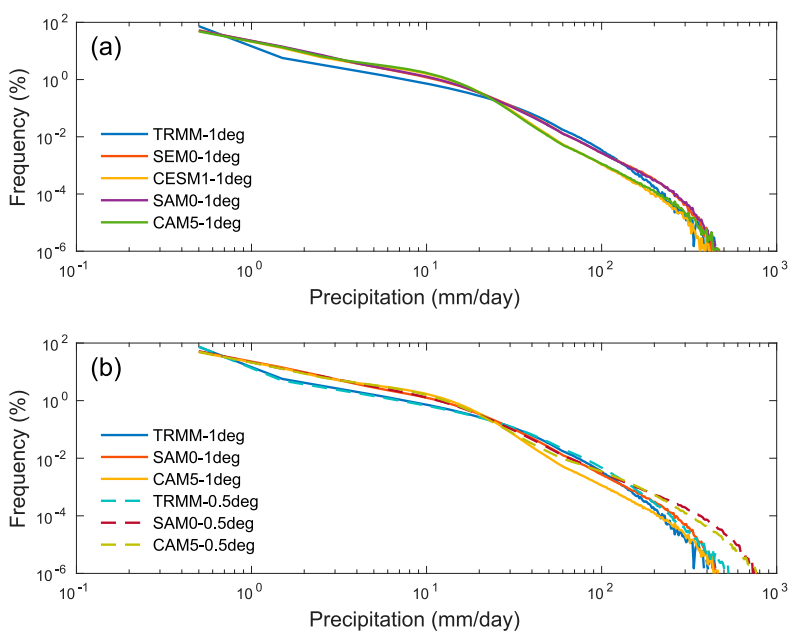

FIG. 6. Frequency spectra of daily surface precipitation rate in the tropical region $\left(30^{\circ} \mathrm{S}-30^{\circ} \mathrm{N}\right)$ obtained from (a) the AMIP and twentieth-century coupled simulations with SAM0/SEM0 and CAM5/CESM 1 at the $1^{\circ}$ lat $\times 1^{\circ}$ lon horizontal resolution and (b) the AMIP simulations with the SAM0 and CAM5 at the $0.5^{\circ}$ lat $\times$ $0.5^{\circ}$ lon and $1^{\circ}$ lat $\times 1^{\circ}$ lon horizontal resolutions compared with the TRMM satellite observations at the same horizontal resolutions during January 2000-December 2009.

area and the $\mathrm{SH}$ circumpolar region along $60^{\circ}-70^{\circ} \mathrm{S}$, which, however, are still persistent and tend to be amplified by the coupling. Parts of these remaining biases seem to be associated with unrealistically high surface albedo in association with a higher sea ice fraction during boreal summer (see Fig. 11). The improved simulation of the sea ice fraction from CESM1 to SEM0 results in the slight reduction of the positive SWCF biases in these regions but further work is necessary to understand and remedy the remaining biases.

Similar to CAM5/CESM1 and other GCMs, SAM0/ SEM0 compute clear-sky (i.e., cloud-free) radiation using the grid-mean water vapor instead of the water vapor in the clear portion, which, as shown by Park (2018), causes the models to underestimate the observed global-mean LWCF (Fig. 7). With this caveat in mind, we identify the following four biases of SWCF and LWCF in SAM0/SEM0 that should be addressed in future version of the models: 1) the horseshoe-patterned biases of SWCF and LWCF over the central tropical Pacific (see the green box area in the figure), which are closely tied to the aforementioned biases of SLP, surface wind, and PRECT; 2) negative biases of SWCF over the North Pacific and Atlantic Oceans during JJA where the model simulates anomalously high SLP; 3 ) negative (positive) biases of SWCF (LWCF) over the tropical continents, indicating that the simulated convection over land is too strong; and 4) strong negative SWCF bias in the far eastern equatorial Pacific Ocean off the coast of Central and South America without corresponding LWCF bias, which seems to be related to a high aerosol optical depth (AOD) (see Fig. 9b) and associated too strong aerosol activation there. More works are necessary to remedy these biases.

\section{5) NEAR-SURFACE AIR TEMPERATURE OVER LAND}

Figure 8 shows the global climatology of the nearsurface air temperature at a height of $2 \mathrm{~m}\left(T_{2 \mathrm{~m}}\right)$ from the Willmott-Matsuura observations during DJF and JJA and the model biases compared to the observations. Overall, SAM0/SEM0 provides improved $\Delta$ mean and RMSE compared to CAM5/CESM1, particularly in the coupled simulation, which produces colder $T_{2 \mathrm{~m}}$ than the uncoupled simulation. Interestingly, the strong positive bias over the central United States during JJA in the uncoupled simulation is substantially reduced by the coupling, which is accompanied by enhanced SLP, PRECT, and SWCF/LWCF, but decreases in tropospheric water vapor specific humidity and moisture static energy from the uncoupled to coupled simulations. In some way (e.g., by the increase of horizontal moisture advection), coupling seems to enhance convective precipitation and associated cloud radiative forcings, which decreases $T_{2 \mathrm{~m}}$ by reflecting the incoming SW radiation and enhancing the upward latent heat flux and also suppresses the associated thermal low. Detailed analysis on these processes may provide important clues necessary to further reduce these biases. Several notable biases in SEM0 are the positive biases over the Europe and central Asia extending to northeastern Asia and Alaska during DJF, which seem to be caused by anomalous warm advection in association with an anomalous north-south SLP dipole over the Europe, Asia, and Alaska (see Fig. 3c); opposite negative biases over the Africa and Saudi Arabia extending into South Asia during DJF, which are accompanied by anomalous high SLP and weaker SWCF/ LWCF; negative biases over far northern Asia and Alaska during JJA, which are also accompanied by stronger SLP and weaker LWCF; the year round weak negative bias over the Amazon; and the biases over Greenland and Antarctica that exist in all simulations with a very similar pattern. Reducing the biases in large-scale flows and associated cloud and precipitation processes would be the first step in improving the simulation of $T_{2 \mathrm{~m}}$.

\section{6) Aerosol optical DePTH}

Figure 9 shows the annual mean AOD from the multisatellite composite observations (Kinne et al. 2006) 
SWCF

OBS (CERES-EBAF)
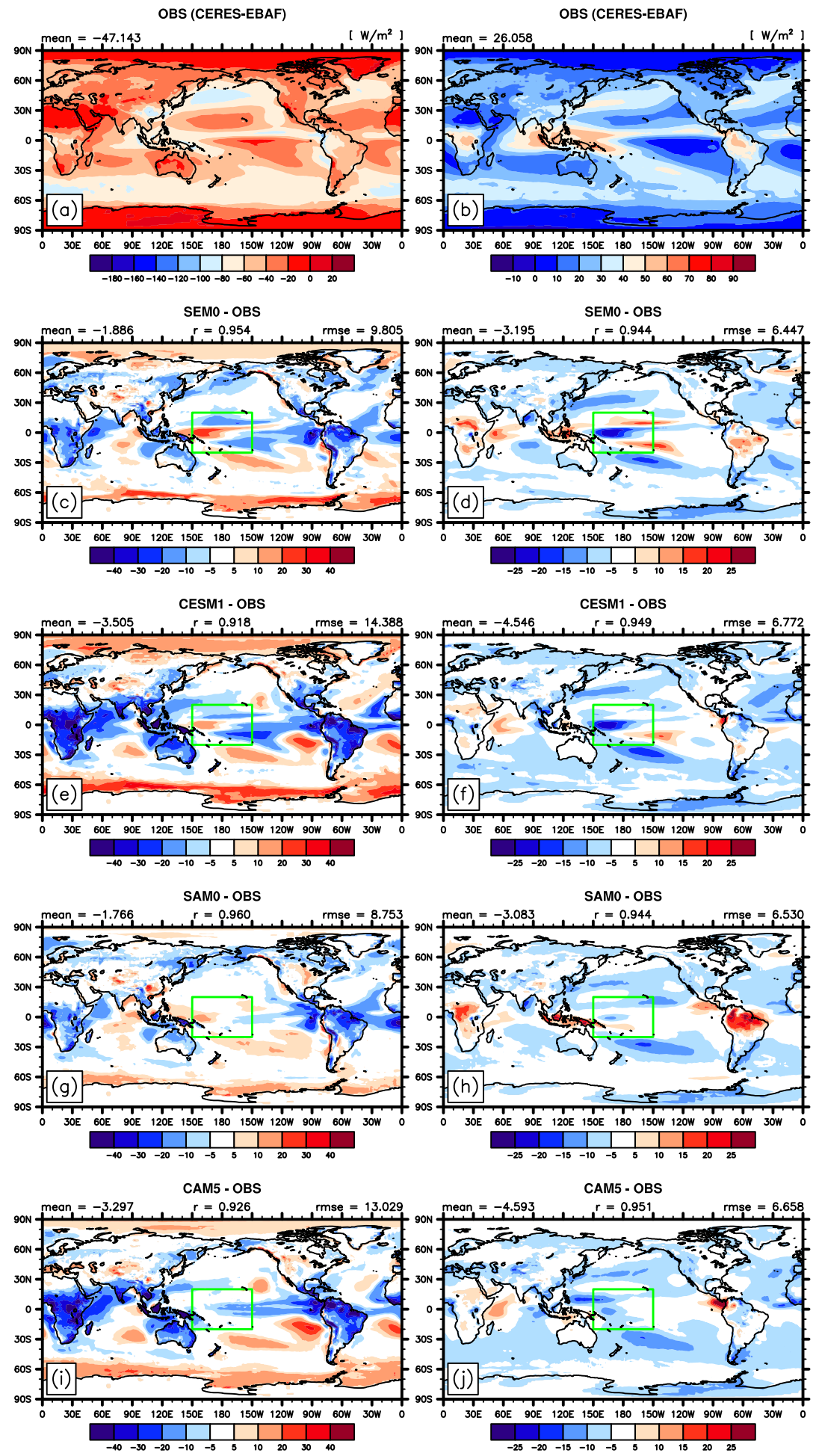

FIG. 7. Annual-mean (a) SWCF and (b) LWCF from the CERES-EBAF observations during March 2000-February 2013, and the biases compared to the observations from (c),(d) SEM0; (e),(f) CESM1; (g),(h) SAM0; and (i),(j) CAM5. 
Air Temperature DJF

OBS (WILLMOTT)

\section{Air Temerature JJA}

OBS (WILLMOTT)

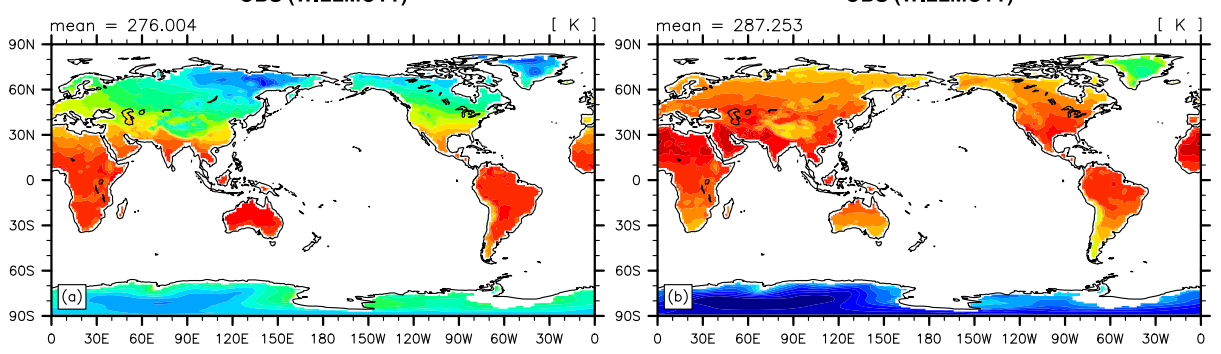

\begin{tabular}{lll|l|l|l|l|l|l|l|l|l|l|l|l|l|l|}
210 & 220 & 230 & 240 & 250 & 260 & 270 & 280 & 290 & 300 & 310
\end{tabular}
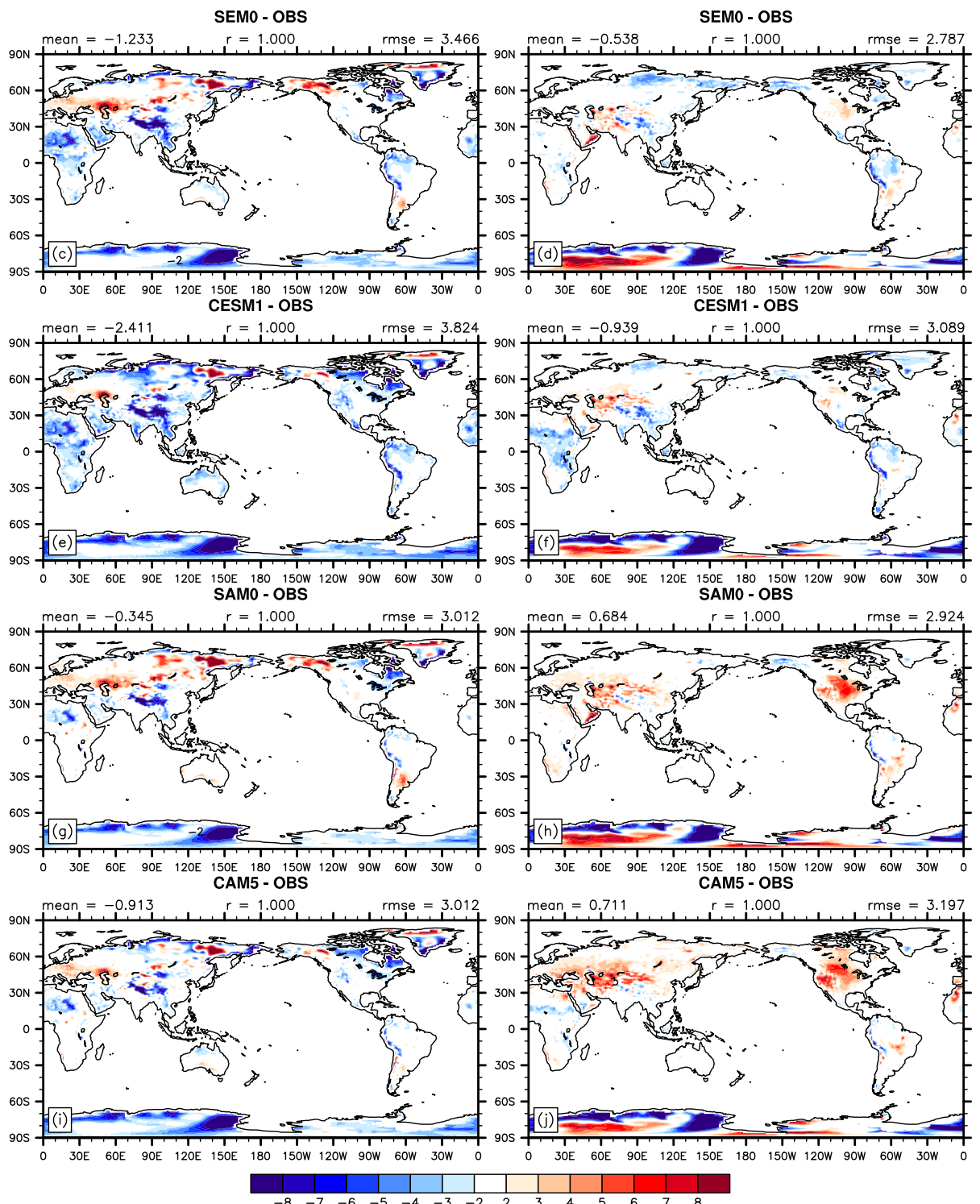

FIG. 8. Near-surface air temperature at 2-m height over land during (a) DJF and (b) JJA from the Willmott observations during January 1950-December 1999, and the biases compared to the observations from (c),(d) SEM0; (e),(f) CESM1; (g),(h) SAM0; and (i),(j) CAM5. 


\section{Aerosol Optical Depth}
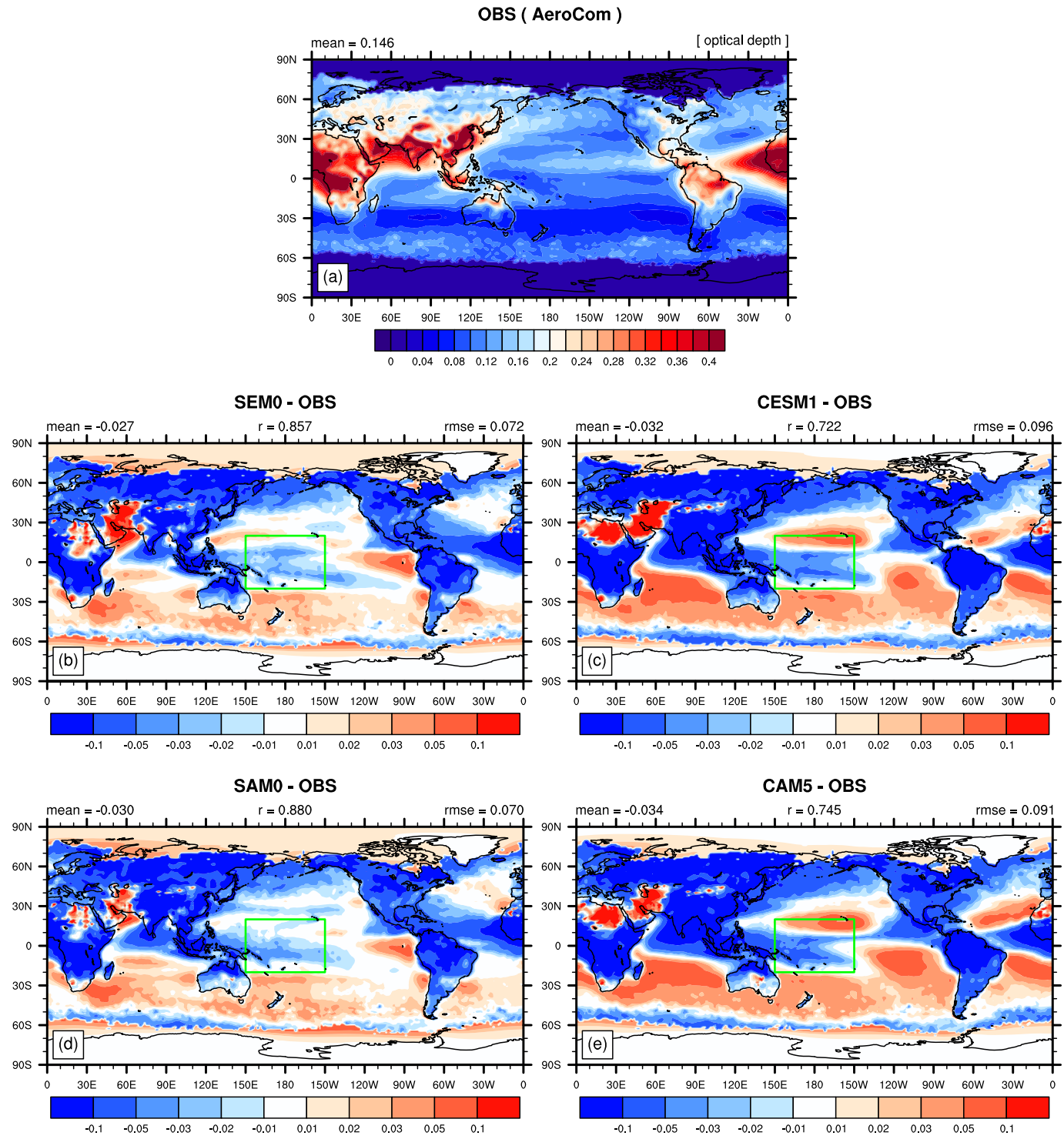

FIG. 9. Annual-mean AOD from (a) the multisatellite composite observations during January 1982-December 2001, and the biases compared to the observations from (b) SEM0, (c) CESM1, (d) SAM0, and (e) CAM5.

and the model biases compared to the observations. Similar to the satellite observation, the models compute AOD using the interstitial aerosols only (i.e., nonactivated aerosols outside of cloud condensates), which are assumed to be horizontally uniform in each grid layer and are advected by the grid-mean flow. To save computation time, the models do not advect the cloud-borne aerosols (i.e., activated and nucleated aerosols within cloud condensates). SAM0/SEM0 produce substantially better $r$ and RMSE than CAM5/ CESM1, which is mainly due to the decrease in strong negative biases in the deep convection regions, particularly over the tropical Pacific area, and the positive biases in the subtropical trade cumulus regions and $\mathrm{SH}$ oceans. However, except over some portions of central Asia and North Africa where dust emissions over desserts are strong, all models simulate an AOD that is too small over the continents and a large AOD over the SH oceans. Because aerosols affect both the radiation budget and hydrological cycle in both models, these AOD biases can influence the other components of the climate system. For example, over the eastern equatorial Pacific Ocean where the simulated AOD is too large, SAM0/SEM0 suffer 
from a SWCF that is too strong without the accompanying biases of LWCF and PRECT, implying that the parameterized aerosol activation may be too strong here. Various processes contribute to the simulated AOD: emissions, subgrid vertical transport, grid-mean transport, wet and dry deposition, and conversion among various aerosol species. A separate study with a set of improved aerosol wet deposition processes with a more realistic vertical cloud overlap parameterization did not remedy these biases (not shown). In contrast to stratiform precipitation, UNICON generates convective precipitation using a bulk single moment cumulus microphysics scheme. Future implementation of a double moment cloud microphysics into UNICON with aerosol activation and ice nucleation processes needs to be accompanied by other efforts to reduce these AOD biases (e.g., revision of aerosol conversion processes), particularly over the continents during summer.

\section{7) ZONAL-MEAN CROSS SECTION}

Figure 10 shows the annual zonal-mean cross sections of temperature $T$, water vapor specific humidity $Q$, relative humidity $(\mathrm{RH})$, zonal wind $U$, and pressure vertical velocity $\omega$ from ERAI and the biases compared to the observations. SEM0 reduces strong cold biases in CESM1 but provides slightly poorer simulations of the other environmental variables. One of the pronounced biases in SEM0 is a drier (i.e., too small $Q$ and $\mathrm{RH}$ ) equatorial troposphere accompanied by anomalous strong subsidence and easterly (westerly) wind in the lower (upper) troposphere, which tend to be amplified from the uncoupled to coupled simulations. These biases are associated with the aforementioned biases of SLP, surface wind, PRECT, SWCF/LWCF, and also cold SST (see Fig. 12) over the central equatorial Pacific Ocean. Other notable biases existing in all simulations are the westerly wind biases centered at $60^{\circ} \mathrm{S}$ in the entire troposphere, which exist in all seasons but are more pronounced during DJF; too cold and moist (i.e., high $\mathrm{RH}$ ) polar upper troposphere centered at $200 \mathrm{hPa}$; anomalous high RH in the midlatitude troposphere and Arctic area, which are accompanied by anomalous high $Q$ centered at $\left(30^{\circ} \mathrm{S}, 800 \mathrm{hPa}\right)$ and cold temperature; and anomalous high temperature and strong upward motion in the Antarctic lower troposphere. More work is necessary to understand and reduce these biases.

\section{8) SEA ICE FRACTION}

Figure 11 shows the annual mean sea ice fraction from the observations and the model biases compared to the observations in the Arctic and Antarctic areas during the present-day and preindustrial periods. The overall bias patterns simulated by SEM0 are roughly similar to those of CESM1 but SEM0 produces better results than CESM1 in terms of the mean bias. During the present day, SEM0 produces a greater sea ice fraction than is observed on the Arctic periphery along $75^{\circ} \mathrm{N}$, with the largest biases over the Barents-Kara and Greenland Seas including Baffin Bay, which, along with the positive bias over the Sea of Okhotsk and far northwestern Pacific Ocean, have been persisting from the preindustrial period with some amplification. Similar positive biases are simulated in the $\mathrm{SH}$ circumpolar region, except in the Weddell Sea between $60^{\circ}$ and $30^{\circ} \mathrm{W}$ during DJF and the portions between $30^{\circ} \mathrm{W}$ and $75^{\circ} \mathrm{E}$ along $60^{\circ} \mathrm{N}$ during JJA, where SEM0 underestimates the observed sea ice fraction. It should be noted that although the positive biases have been amplified, the simulated sea ice fraction has been decreasing from the preindustrial to present-day periods. The positive biases of sea ice fraction in the $\mathrm{SH}$ circumpolar region are collocated with the positive biases of surface wind stress, implying that strong upward heat flux at the surface and oceanic Ekman transport (both horizontal and vertical) associated with strong surface wind may contribute to these positive biases of sea ice fraction. In turn, a greater sea ice fraction in the SH circumpolar region may enhance surface westerly wind by strengthening the meridional temperature gradient across the boundary of the enhanced sea ice fraction and the associated midlatitude jet stream. As mentioned before, some of the positive biases of SWCF in the SH circumpolar region during DJF (Fig. 7) are likely due to a greater much sea ice fraction and associated high surface albedo.

\section{9) SEA SuRface Temperature}

Figure 12 shows the annual-mean SST from the observations and the model biases compared to the observations during the present-day and preindustrial periods. In terms of the mean and RMSE biases, SEM0 produces more realistic SST than does CESM1, which simulates colder SST than SEM0 in most areas. The bias pattern during the present day is roughly similar to that during the preindustrial period, but the global mean negative biases have been amplified in CESM1. The largest biases in SEM0 are the strong negative biases in the vicinity of the Labrador Sea and the northwestern Pacific Ocean along $35^{\circ} \mathrm{N}$ that is particularly strong in JJA. During DJF, the strong cold bias in the Labrador Sea and the weaker cold bias in the tropical and subtropical Atlantic Ocean are separated by a zone containing a weak warm SST anomaly but they are connected during JJA. It is speculated that these negative SST biases originate from the positive 

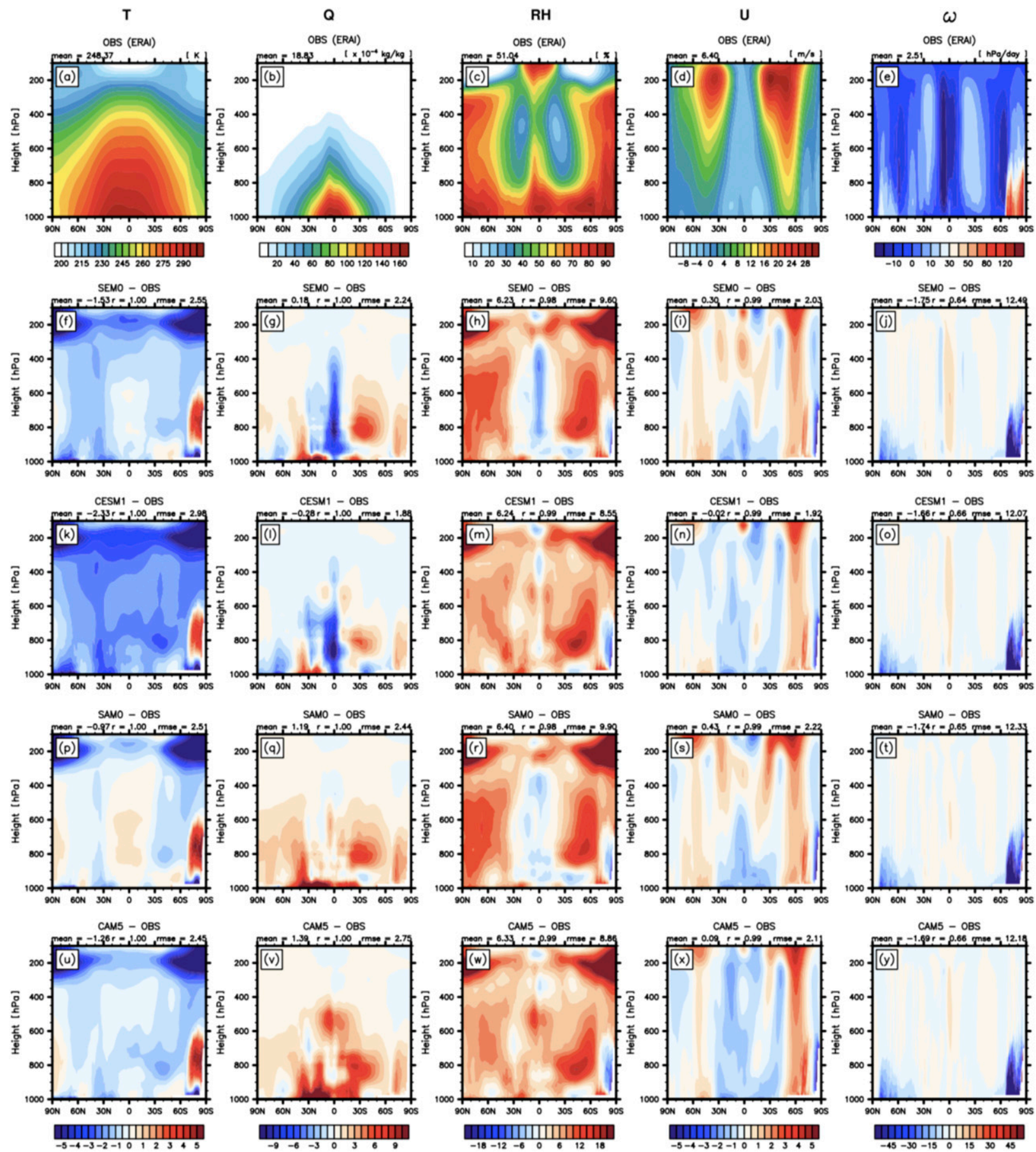

FIG. 10. Annual zonal-mean cross sections of (first column) temperature, (second column) water vapor specific humidity, (third column) relative humidity, (fourth column) zonal wind, and (fifth column) pressure-vertical velocity from (a)-(e) the ERAI observations during January 1985-December 2014, and the biases compared to the observations from (f)-(j) the SEM0, (k)-(o) CESM1, (p)-(t) SAM0, and (u)-(y) CAM5.

biases of sea ice fraction in the nearby Sea of Okhotsk and northwestern Bering Sea in the Pacific sector and the Barents-Kara and Greenland Seas including the Baffin Bay in the Atlantic sector (see Fig. 11), which seem to be also responsible for the negative SST biases in the far northwestern Pacific Ocean, including the narrow stripe along the southern coast of Alaska and the Aleutian Islands and also in the Greenland-Norwegian 

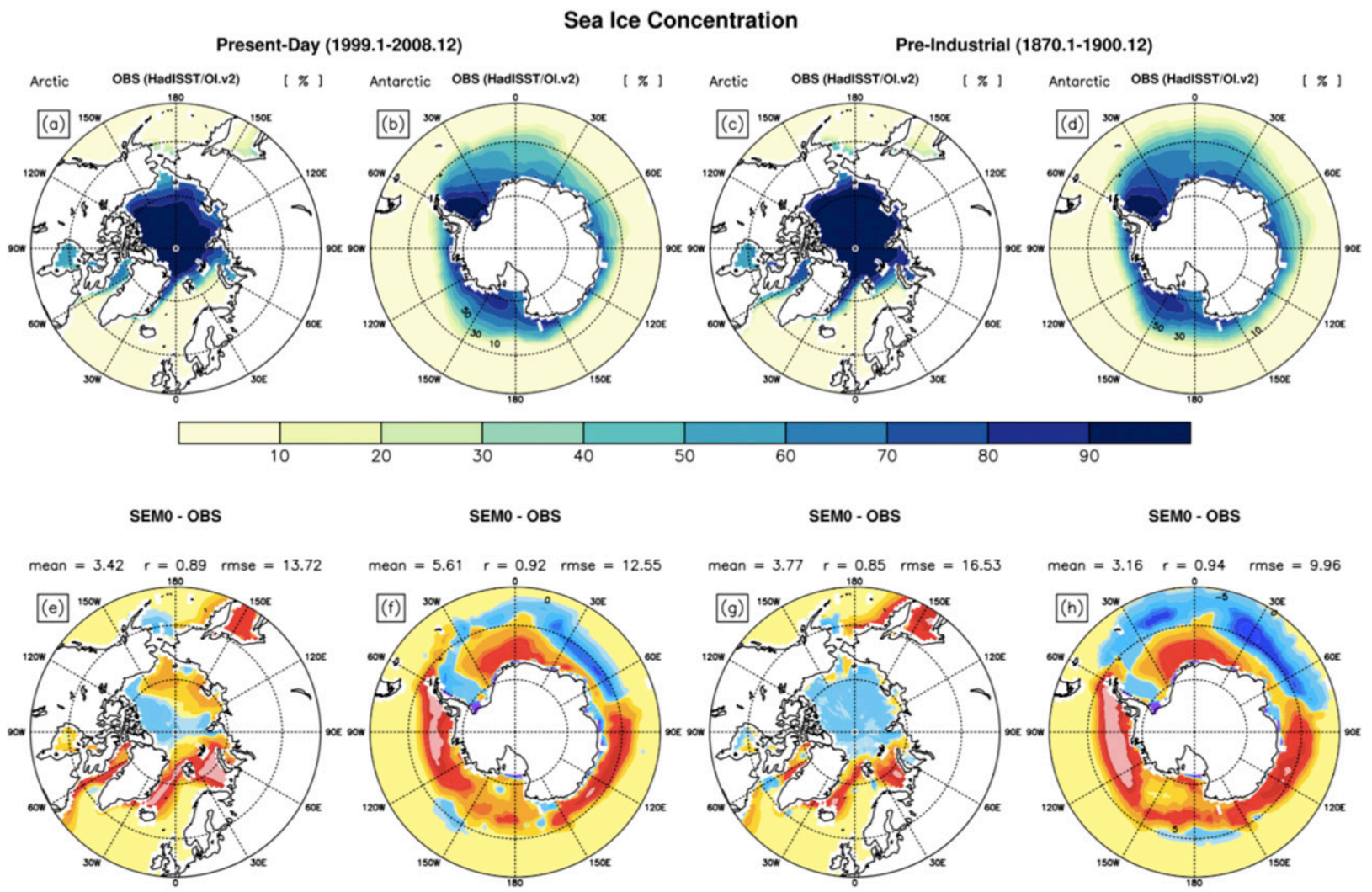

CESM1 - OBS

CESM1 - OBS

CESM1 - OBS

CESM1 - OBS

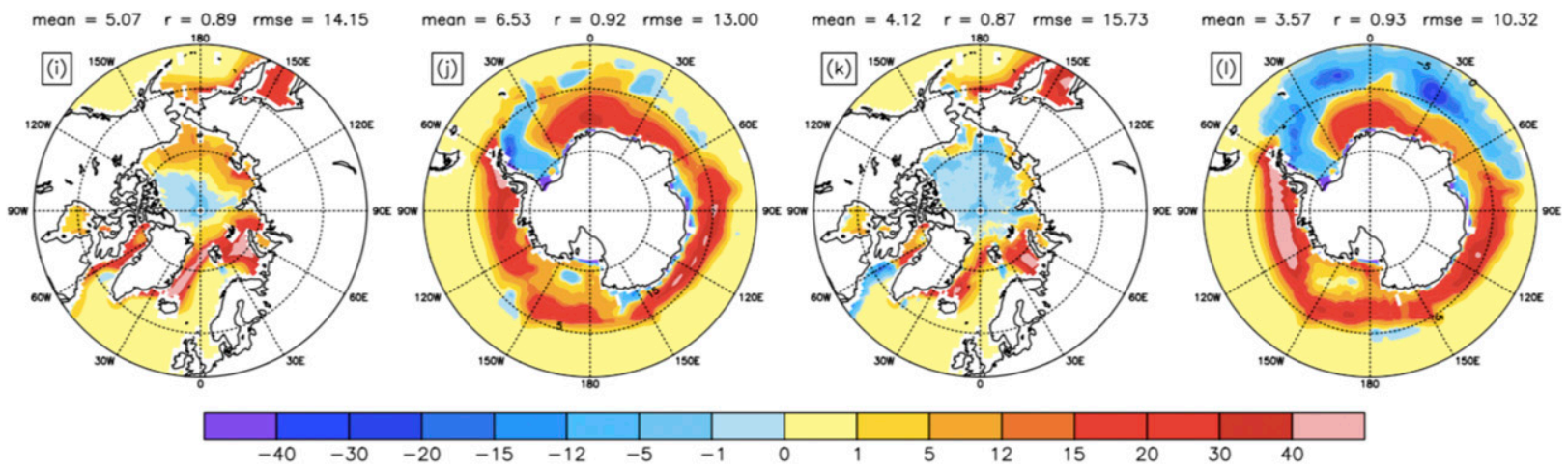

FIG. 11. Annual-mean sea ice fraction over the Arctic and Antarctic areas during (first two columns) the PD (January 1999-December 2008) and (last two columns) PI (January 1870-December 1900) periods from (a)-(d) the HadISST/OI.v2 observation (Rayner et al. 2003), and the biases compared to the observations from the twentieth-century coupled simulations with (e)-(h) SEM0 and (i)-(j) CESM1 during the same period.

Sea on the west of the Barents Sea. A similar association between the biases of sea ice fraction and SST seems to exist in the SH circumpolar region: SEM0 produces negative SST biases in the Pacific Ocean sector and positive SST biases in the Atlantic and Indian Ocean sectors, which are roughly coherent with the biases of sea ice fraction (see Fig. 11f). The summertime enhancement of negative SST biases in the northwestern Pacific Ocean may be due in part to the positive radiative feedback between SST and stratocumulus that favors cold SST for its formation and cools the underlying sea surface by reflecting incoming SW radiation. A comparison of Fig. 12c with Fig. $4 \mathrm{c}$ indicates that some of the positive SLP biases over the North Pacific and North Atlantic Oceans during JJA may come from the hydrostatic adjustment 
Present-Day (1999.1-2008.12) OBS (HadISST/OI.v2)

Sea Surface Temperature

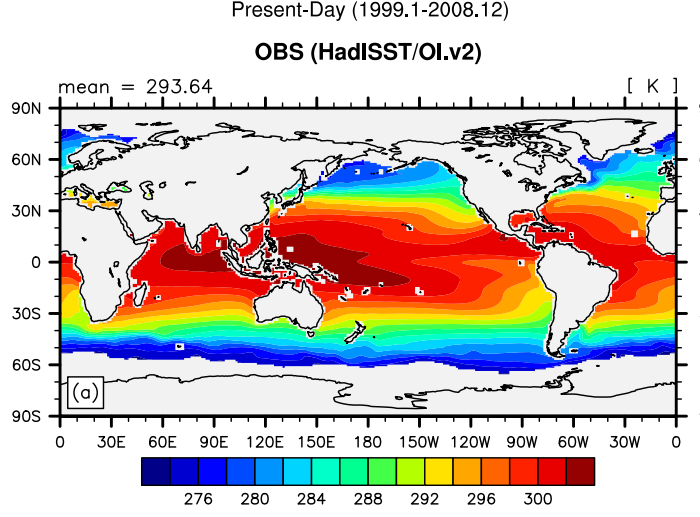

SEMO - OBS

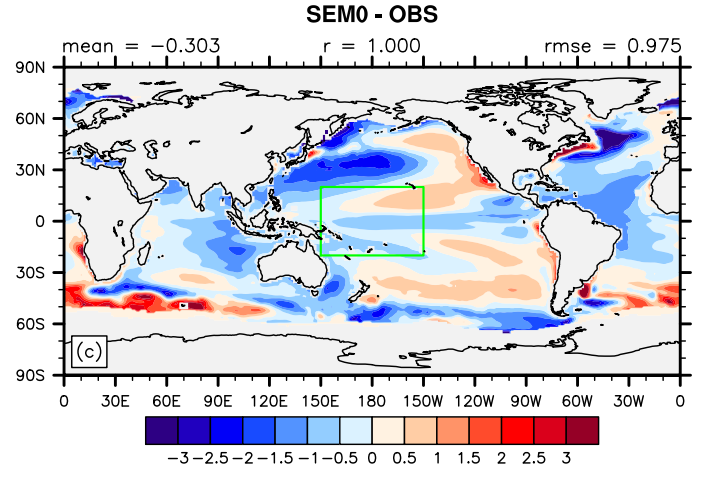

CESM1 - OBS
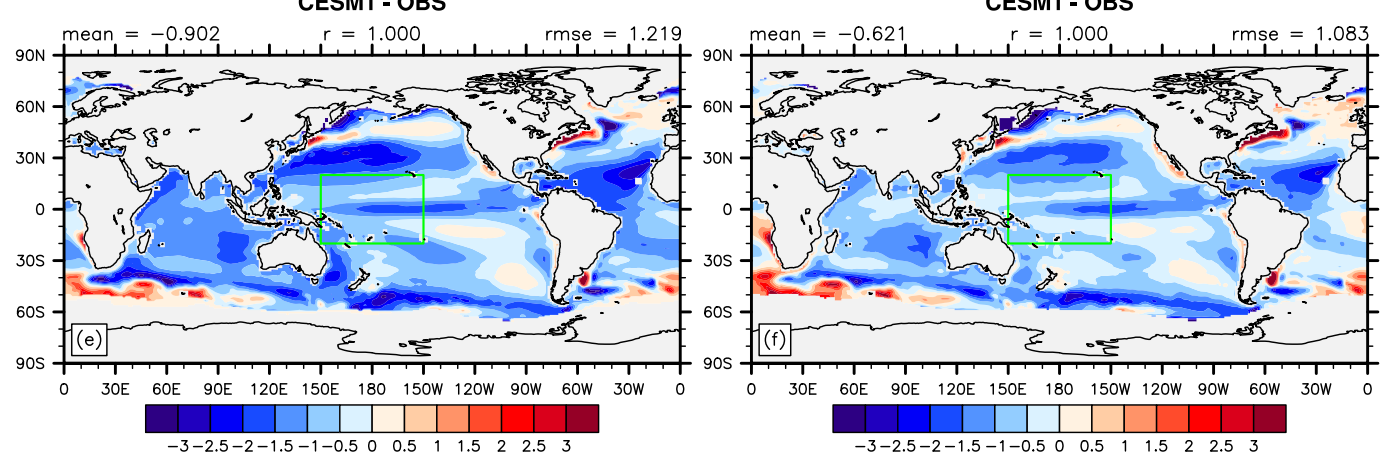

FIG. 12. Annual-mean SST from the HadISST/OI.v2 observation (Rayner et al. 2003) during (a) PD (January 1999-December 2008) and (b) PI (January 1870-December 1900) periods and the biases compared to the observations from the twentieth-century coupled simulations with (c),(d) SEM0 and (e),(f) CESM1 during the same period.

of SLP to underlying cold SST generated by an excessive sea ice fraction.

Although relatively small in magnitude, the most important SST biases are the negative bias along the equatorial Pacific Ocean and the positive biases in the nearby off-equatorial oceans, which are tied to the positive bias of easterly surface wind along the equator. It is speculated that the equatorial Ekman upwelling driven by anomalous easterly surface wind and the drift of surface water to off-equatorial regions generate these SST anomalies. The hydrostatic adjustment of tropical SLP to underlying SST and the associated changes of atmospheric mean flow, clouds, and precipitation processes are likely to reinforce the aforementioned horseshoe-patterned biases of SLP, surface wind, PRECT, SWCF/LWCF, and SST in the central equatorial Pacific. The anomalous tropical diabatic heating can modulate various aspects of the midlatitude climate system through the changes of the Hadley circulation or Rossby waves propagating from the tropics to the extratropics. In SEM0, the negative SST biases in the southeastern Indian Ocean centered 


\section{OBS}
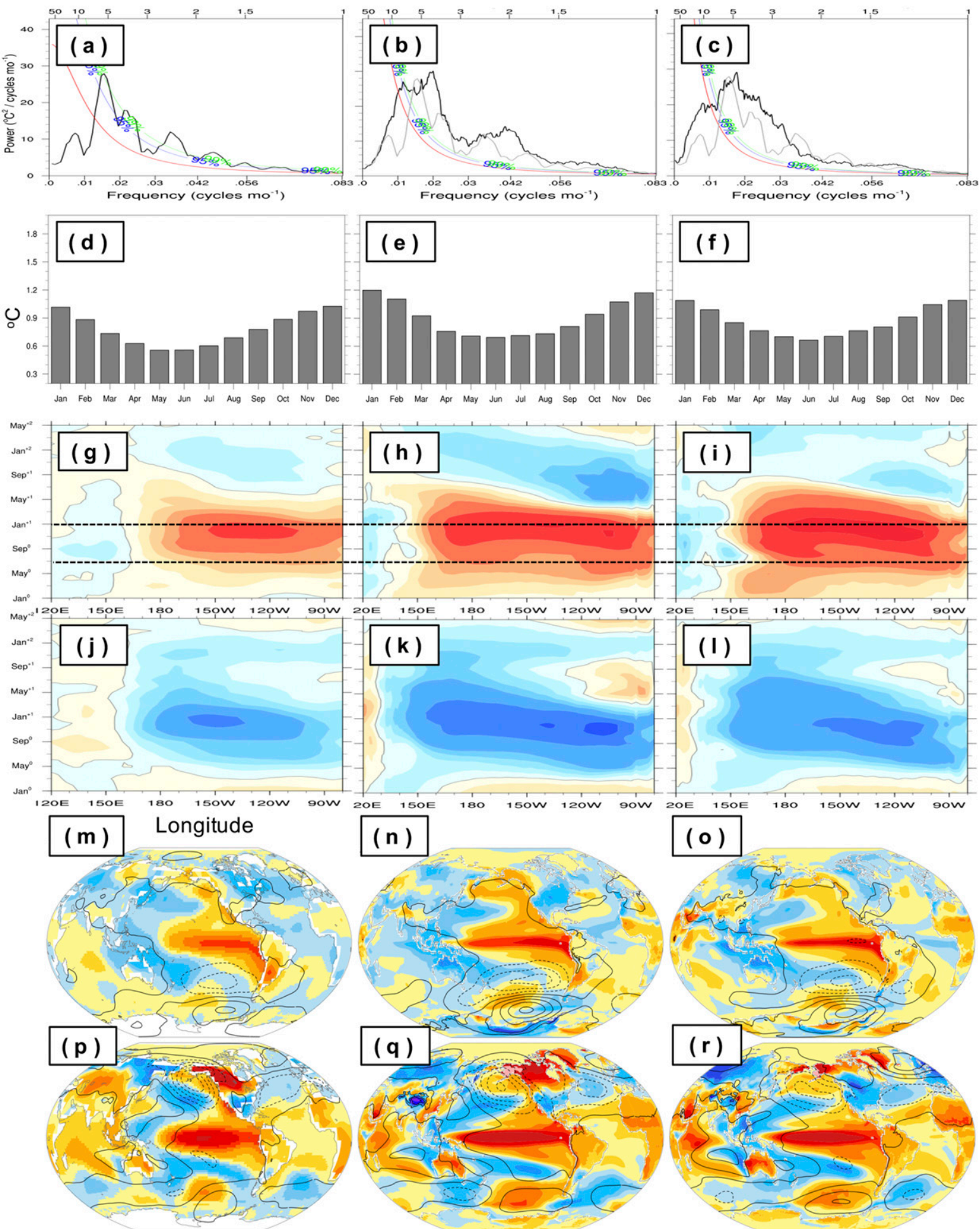

FIG. 13. ENSO: (a)-(c) Power spectra of detrended monthly Niño-3.4 SST anomalies, (d)-(f) monthly standard deviation of Niño-3.4 SST anomalies, (g)-(l) the Hovmöller diagrams of equatorial SST anomalies averaged over $3^{\circ} \mathrm{S}-3^{\circ} \mathrm{N}$ during (g)-(i) El Niño and (j)-(l) La Niña events, and the spatial composite patterns of surface temperature and SLP on the Niño-3.4 index during (m)-(o) JJA of the El Niño year and (p)-(r) DJF in the next year of the El Niño events obtained from (left) the ERSSTv3b/MLOST/ReanaV2 observations (Rayner et al. 2003) during January 1910 and December 2011 and the 500 years of 1850 preindustrial coupled simulations with (middle) SEM0 and (right) CESM1. 
OBS SEMO

CESM1

SAMO

CAM5
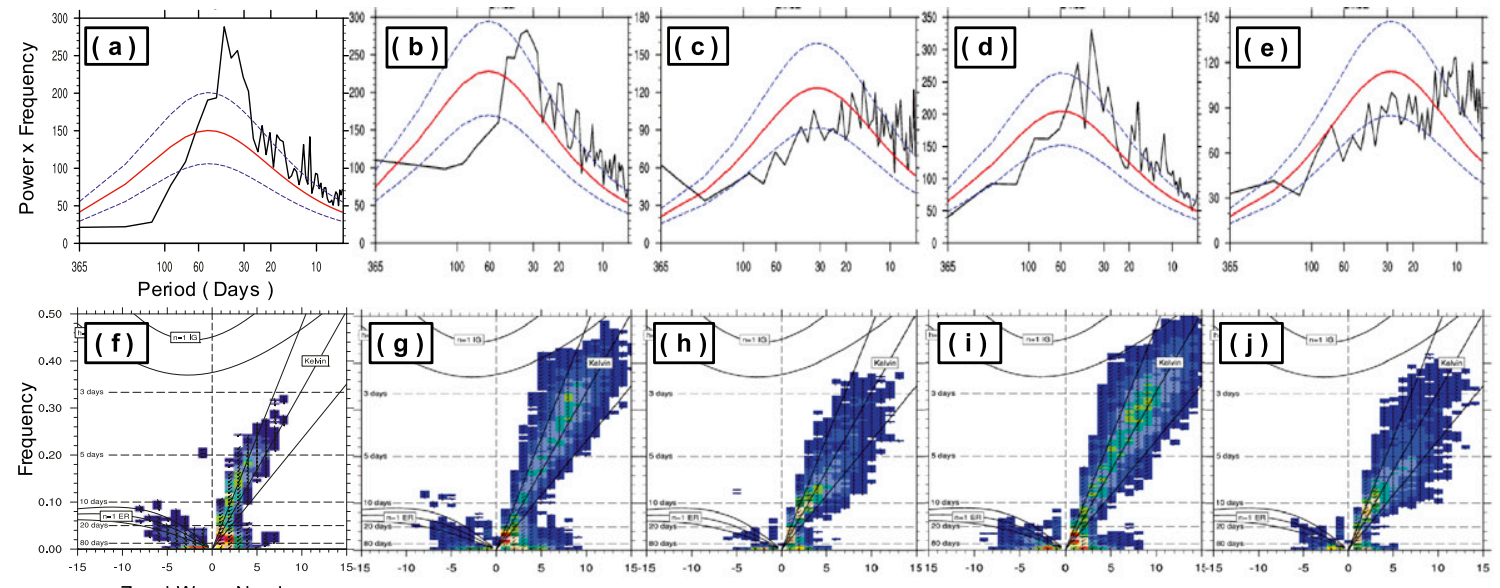

Zonal Wave Number

\begin{tabular}{lllllllllll}
\hline 0.05 & 0.15 & 0.25 & 0.35 & 0.45 & 0.55 & 0.65 \\
\hline
\end{tabular}
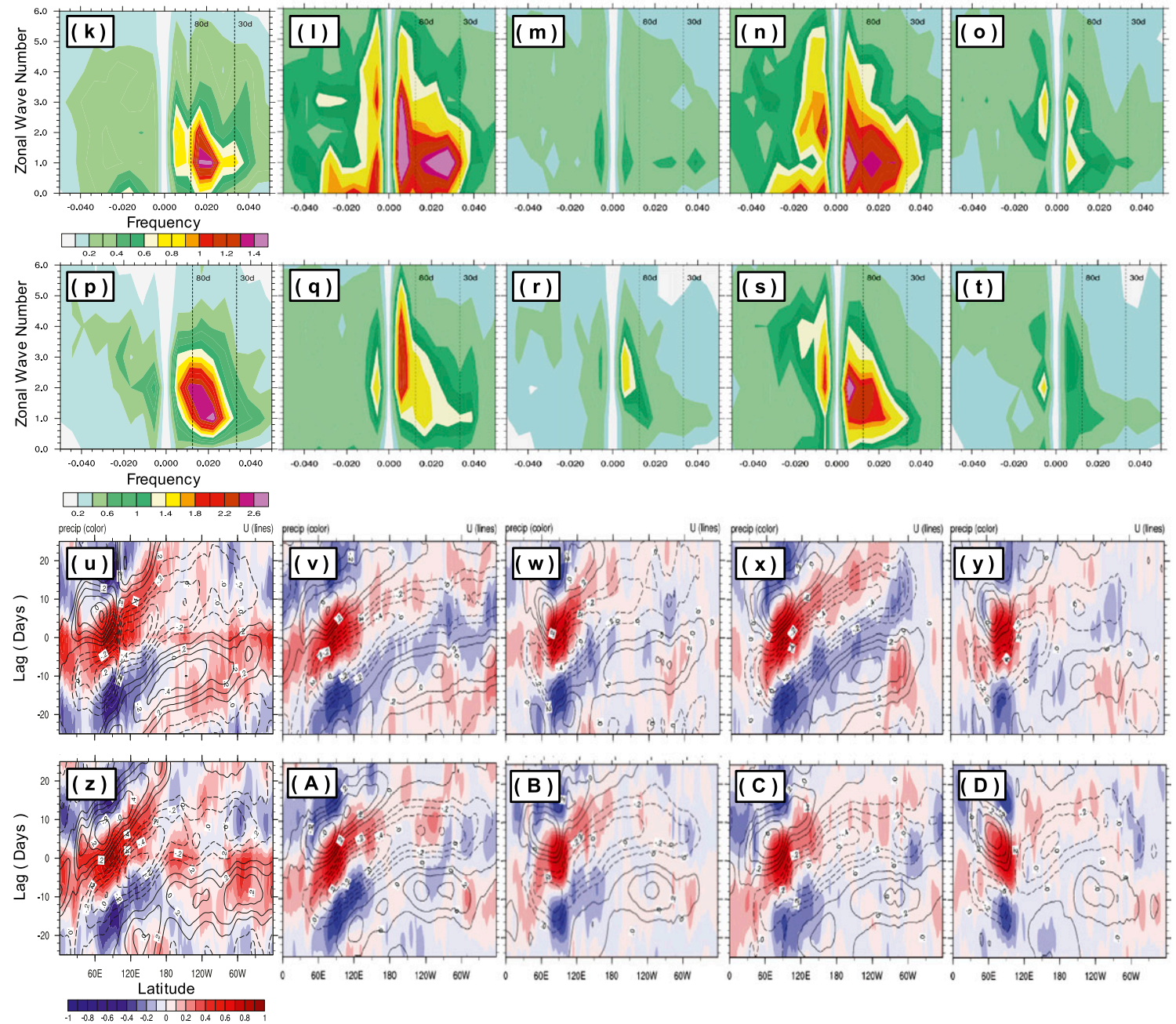

FIG. 14. MJO: (a)-(e) the power spectrum of daily OLR anomalies averaged over the Indian Ocean $\left(10^{\circ} \mathrm{S}-5^{\circ} \mathrm{N}, 75^{\circ-} 100^{\circ} \mathrm{E}\right)$ with the lines denoting the null (red line), 5\% (lower blue dotted), and 95\% (upper blue dotted) red-noise significance levels; (f)-(j) the symmetric component of coherence squared obtained from the cross-spectrum analysis of daily anomalies of OLR and zonal wind at $850 \mathrm{hPa}$ (U850) in the latitude band between $15^{\circ} \mathrm{S}$ and $15^{\circ} \mathrm{N} ;(\mathrm{k})-(\mathrm{o}),(\mathrm{p})-(\mathrm{t})$ The wavenumber-frequency spectra of daily anomalies of OLR averaged over 
at $\left(15^{\circ} \mathrm{S}, 100^{\circ} \mathrm{E}\right)$ and tropical Atlantic Ocean collocate with the negative biases of LWCF, while the positive SST biases along the western coasts of North and South America during JJA and also in the SH ocean during DJF collocate with the positive biases of SWCF. This implies that radiative feedback between clouds and SST may contribute to these SST biases. Additional sensitivity studies are planned to verify various hypotheses on the sources of the SST biases mentioned above.

\section{c. Variability}

\section{1) ENSO}

Figure 13 shows the analysis of ENSO performed by using the NCAR Climate Analysis Section's Climate Variability Diagnostics Package (Phillips et al. 2014). In this plot, the El Niño and La Niña events are defined as the years when the standardized detrended monthly Niño-3.4 SST anomalies during November-January are larger than 1 and smaller than -1 , respectively. Both SEM0 and CESM1 well reproduce the observed power peak of the Niño-3.4 SST anomalies at the period of 4-7 years but simulate an unrealistic continuous significant power in periods shorter than 3 years. Although the magnitude is slightly larger than the observations, the annual cycle of the simulated monthly standard deviation of Niño-3.4 SST anomalies is also similar to the observation with a minimum value during late spring and early summer and a maximum value during winter. The Hovmöller diagrams of equatorial SST anomalies averaged over $3^{\circ} \mathrm{S}-3^{\circ} \mathrm{N}$ show that both models reasonably reproduce the observed evolution of tropical SST anomalies during the El Niño/La Niña events, but the node of the simulated SST anomalies (i.e., the longitude with zero anomaly) is extended too far westward compared to the observations, particularly during the La Niña events. During the developing phase of the El Niño, the observation does not show clear zonal propagation signals of SST anomalies, and SEM0 seems to reproduce this observation slightly better than CESM1. However, SEM0 simulates a somewhat stronger La Niña right after the El Niño (and also stronger El Niño right after La
Niña) in the eastern equatorial Pacific Ocean compared to the observation and CESM1 simulation. The simulated spatial composite patterns of surface temperature and SLP in JJA ${ }^{0}$ and $\mathrm{DJF}^{+1}$ during the El Niño are roughly similar to the observations. However, as mentioned above, the simulated positive SST anomalies in the tropical Pacific Ocean extends too far westward in both models. During the El Niño, SEM0 better reproduces the observed warming/cooling in the northern/southern North America in $\mathrm{DJF}^{+1}$ while CESM1 does slightly better in $\mathrm{JJA}^{0}$ in this region. Both models, particularly SEM0, simulate stronger cooling over the Tibetan Plateau than the observation during $\mathrm{DJF}^{+1}$. It is interesting to note that even though subgrid convective momentum transport in SEM0 is set to be weaker than in CESM1, both models produce a similar ENSO. This implies that as well as convective momentum transport which was shown to be important for the proper simulation of ENSO in GCMs (e.g., Neale et al. 2008; Richter and Rasch 2008), some other processes (e.g., fractional entrainment of environmental air into convective updraft) also contribute importantly to ENSO. Although differences exist in detailed aspects, SEM0 is as good as CESM1 in reproducing the observed ENSO.

\section{2) MADDEN-JULIAN OSCILLATION}

Figure 14 shows various diagnostic plots for the MJO. The power spectrum analysis of daily anomalies of OLR (outgoing longwave radiation) averaged over the Indian Ocean shows that in contrast to CAM5/ CESM1, SAM0/SEM0 successfully capture the observed MJO-related power peak above the $95 \%$ red noise significance level at a period of 25-50 days (Figs. 14a-e). The cross-spectrum analysis of the observed daily anomalies of OLR and zonal wind at $850 \mathrm{hPa}$ (U850) in the latitude band between $15^{\circ} \mathrm{S}$ and $15^{\circ} \mathrm{N}$ shows strong coherency for a period of 30 80 days and a zonal wavenumber of 1-2 (Fig. 14f). Although slightly weaker than the observation, SAM0/ SEM0 reproduces the observed strong coherency better than CAM5/CESM1, which simulate too weak a coherency in the MJO regime. SAM0/SEM0 also work better than CAM5/CESM1 in reproducing the observed

the latitude band between $10^{\circ} \mathrm{S}$ and $10^{\circ} \mathrm{N}$ during summer (May-October) and winter (November-April), respectively; and (u)-(y),(z)-(D) The lead-lag correlations of the 20-100-day bandpass-filtered, daily PRECT (color shading) and U850 (solid dashed line) correlated to the daily time series of bandpass-filtered PRECT at $\left(0^{\circ}, 90^{\circ} \mathrm{E}\right)$ as a function of longitude during summer (May-October) and winter (November-April), respectively. The observations are from the AVHRR satellite-observed OLR (Liebmann and Smith 1996) and the NCEP-NCAR reanalysis U850 (Kalnay et al. 1996) during January 1979-December 2005 and the GPCP PRECT during January 1996December 2008. 
(a) OBS
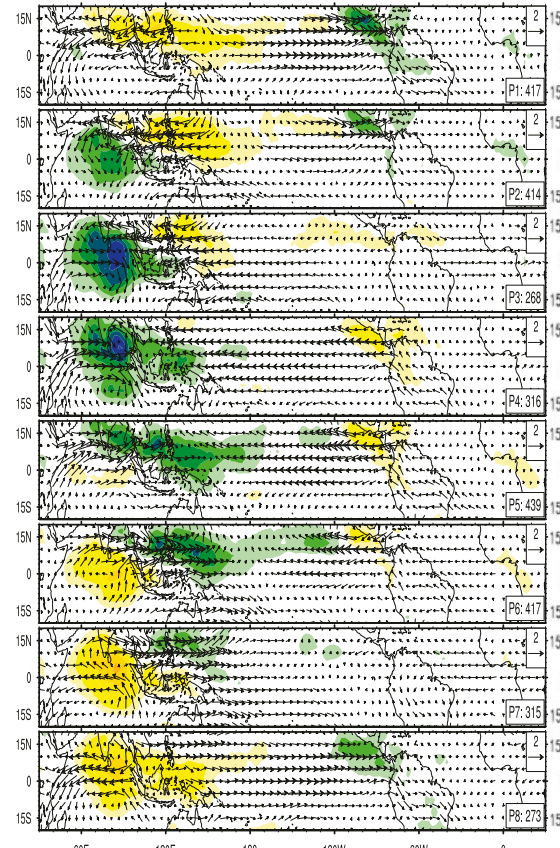

(d)
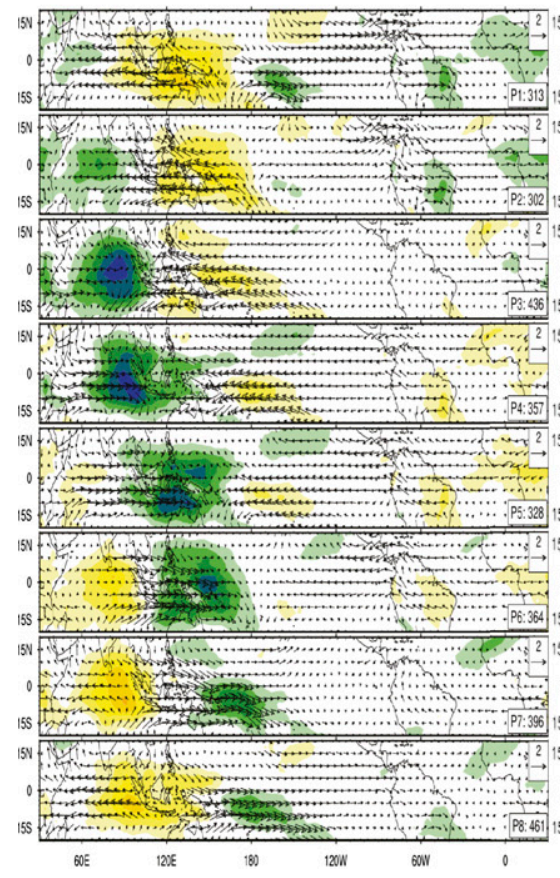

$-40$

\section{(b) SEMO}
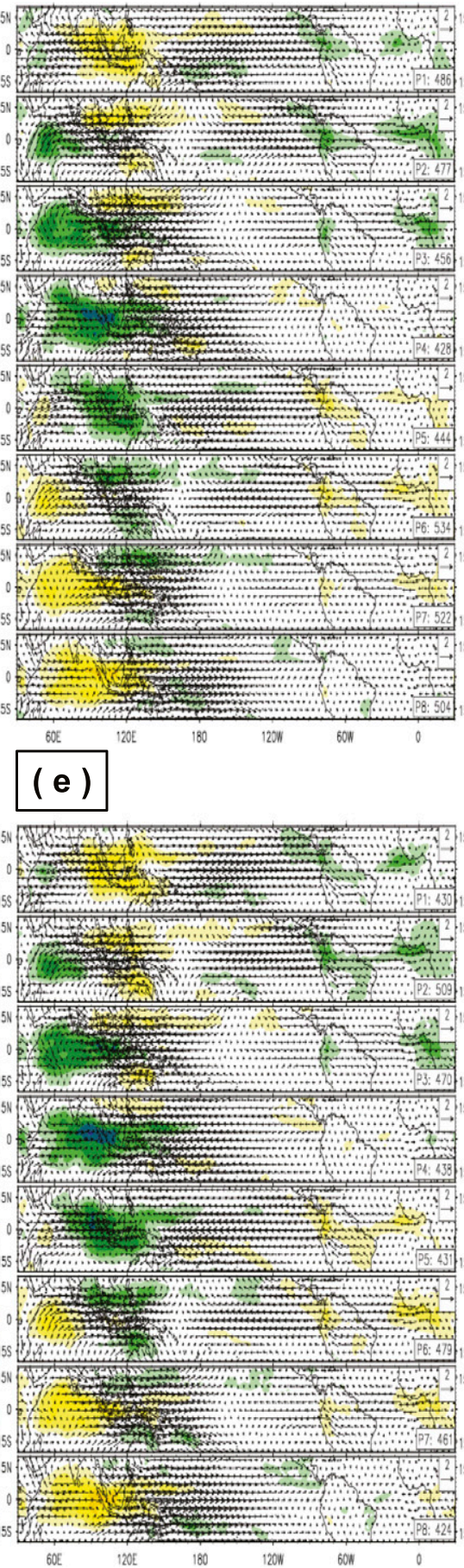

\section{(c) CESM1}
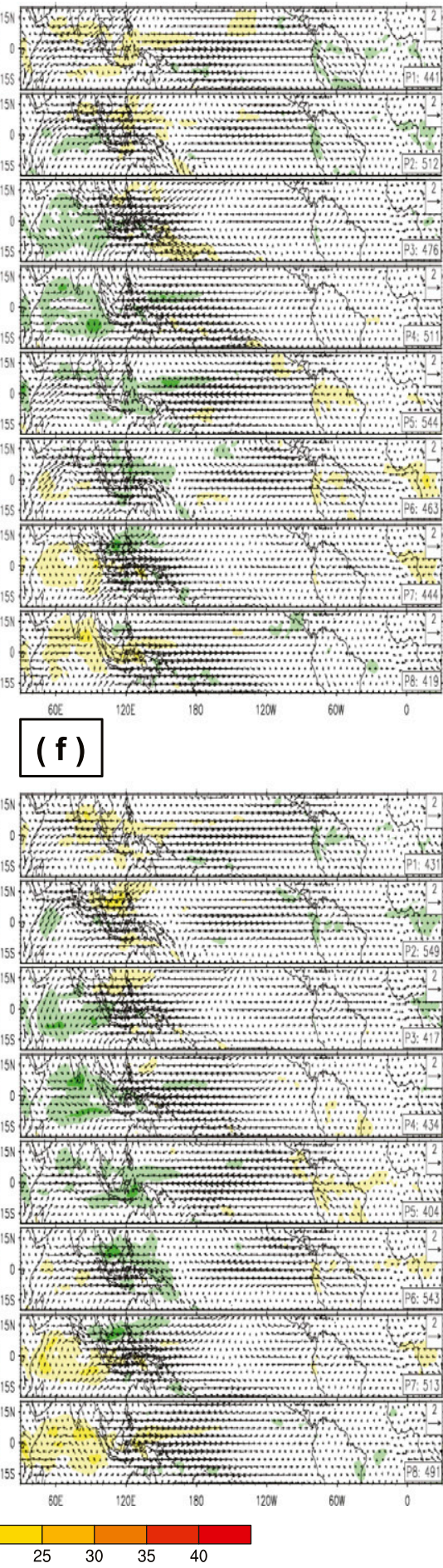

FIG. 15. MJO: the composite life cycle of the 20-100-day bandpass-filtered, daily anomalies of OLR (color) and wind vectors at $850 \mathrm{hPa}$ during (a)-(c) May-October and (d)-(f) November-April. The time series corresponding to the first and second EOF modes of the year round multivariate EOF analysis of OLR, U850, and U200 are used to derive appropriate categories of the MJO phase for the composite. In each composite plot, the size of the reference anomaly wind vector $\left(\mathrm{m} \mathrm{s}^{-1}\right)$ is in the upper right, and the phase (e.g., P1 means phase 1) and number of days used to create the composite are at the lower right. The observations are from the AVHRR satellite observed OLR and the NCEP-NCAR reanalysis wind vectors during January 1979-December 2005. 


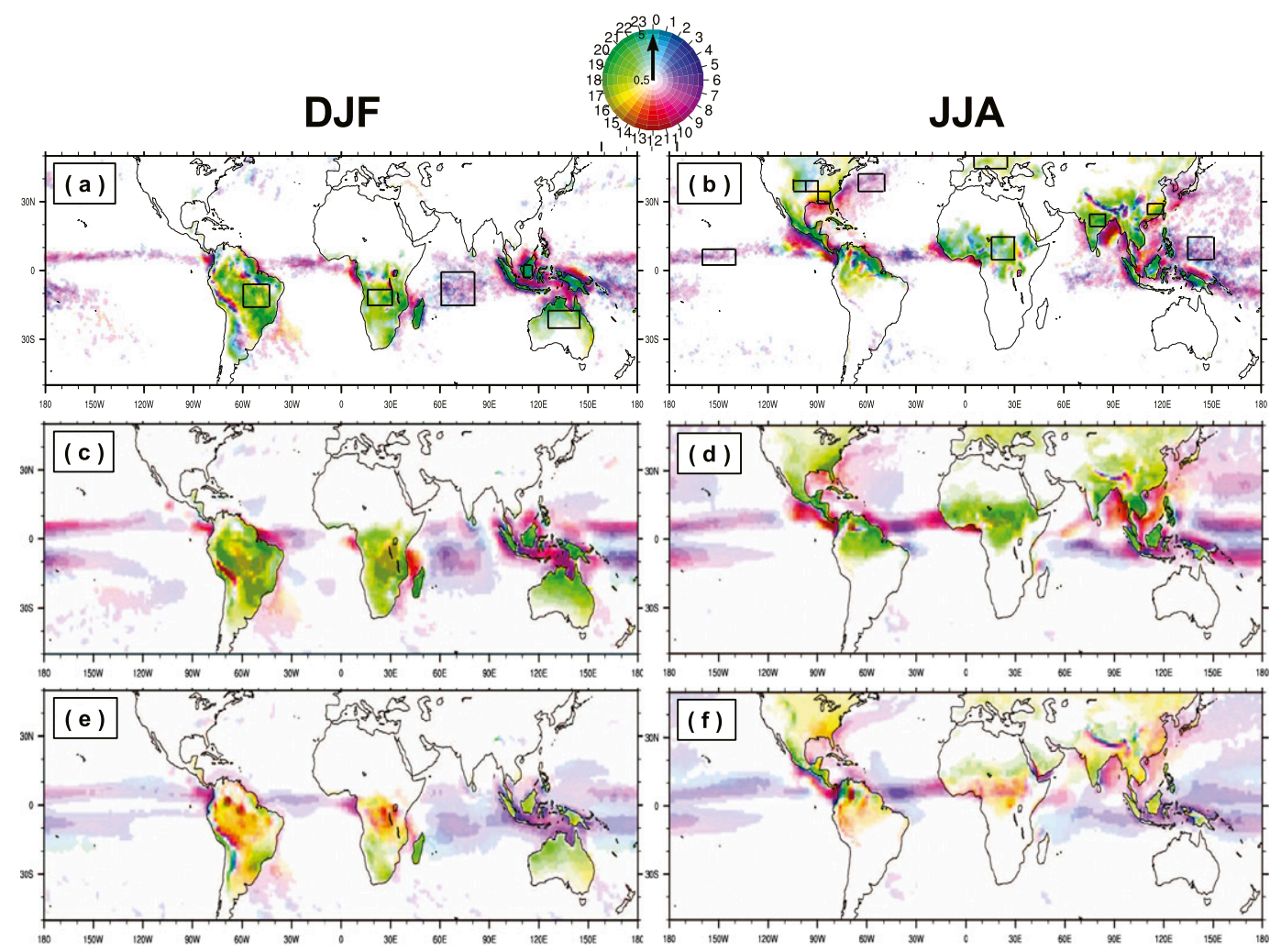

FIG. 16. The diurnal cycle of the total precipitation rate at the surface during (left) DJF and (right) JJA from (a),(b) the TRMM satellite observations during January 2000-December 2009; (c),(d) SAM0; and (e),(f) CAM5. The color scale denotes the local hour when the surface precipitation rate fitted to the first harmonic function is a maximum, and the hue scale denotes the amplitude of the diurnal cycle.

Kelvin and Rossby waves. The wavelet analysis of daily anomalies of OLR during summer and winter also reveals that SAM0/SEM0 is much better than CAM5/CESM1 in reproducing the observed power in the MJO period of 30-80 days with a zonal wavenumber of 1-2 (Figs. 14k-t). However, compared to the observation, SAM0/SEM0 simulates a variability that is too strong in the lowfrequency regime and a weaker MJO power during winter. In SAM0/SEM0 (and also CAM5/CESM1), coupling of the atmosphere with an interactive ocean is not very helpful in reducing these biases and slightly degrades the MJO power during winter. It is interesting to note that SAM0 and SEM0 reasonably reproduce the observed MJO, implying that the coupling is not critical for simulating the MJO.

The lead-lag correlation analysis of the observed 20100-day bandpass-filtered, daily PRECT and U850 correlated to the daily time series of PRECT at $\left(0^{\circ}, 90^{\circ} \mathrm{E}\right)$ clearly shows the eastward propagation of the MJOrelated mesoscale precipitation system and associated low-level wind convergence (Figs. 14u,z). SAM0/SEM0 reproduces this observed propagation better than do CAM5/CESM1 but the simulated eastward propagation of PRECT across $150^{\circ} \mathrm{E}$ seems to be substantially weaker than the observation during winter. This weaker propagation in the model can be seen more clearly in the composite life cycle of daily anomalies of OLR and wind vectors at $850 \mathrm{hPa}$ (Fig. 15). Although much better than CESM1, SEM0 simulates substantially weaker tropical deep convection than the observations after the MJO phase 5 to the east of $150^{\circ} \mathrm{E}$ during winter with a slower eastward propagation. It is speculated that this is due in part to the biases in the simulated mean climate over the central equatorial Pacific Ocean, that is, anomalous high SLP, cold SST, dry troposphere and strong subsidence (see the green box area in the previous figures), which provides unfavorable conditions for the growth of deep convection in front of the propagating mesoscale convective system. The aforementioned degradation of the MJO by the coupling during winter is also likely to be associated with the degradation of the mean state.

\section{3) DiURNAL CYCLE OF PRECIPITATION}

Figure 16 shows the diurnal cycle of precipitation rate at the surface from the 3-hourly TRMM observations, 


\section{Diurnal Cycle of Precipitation}
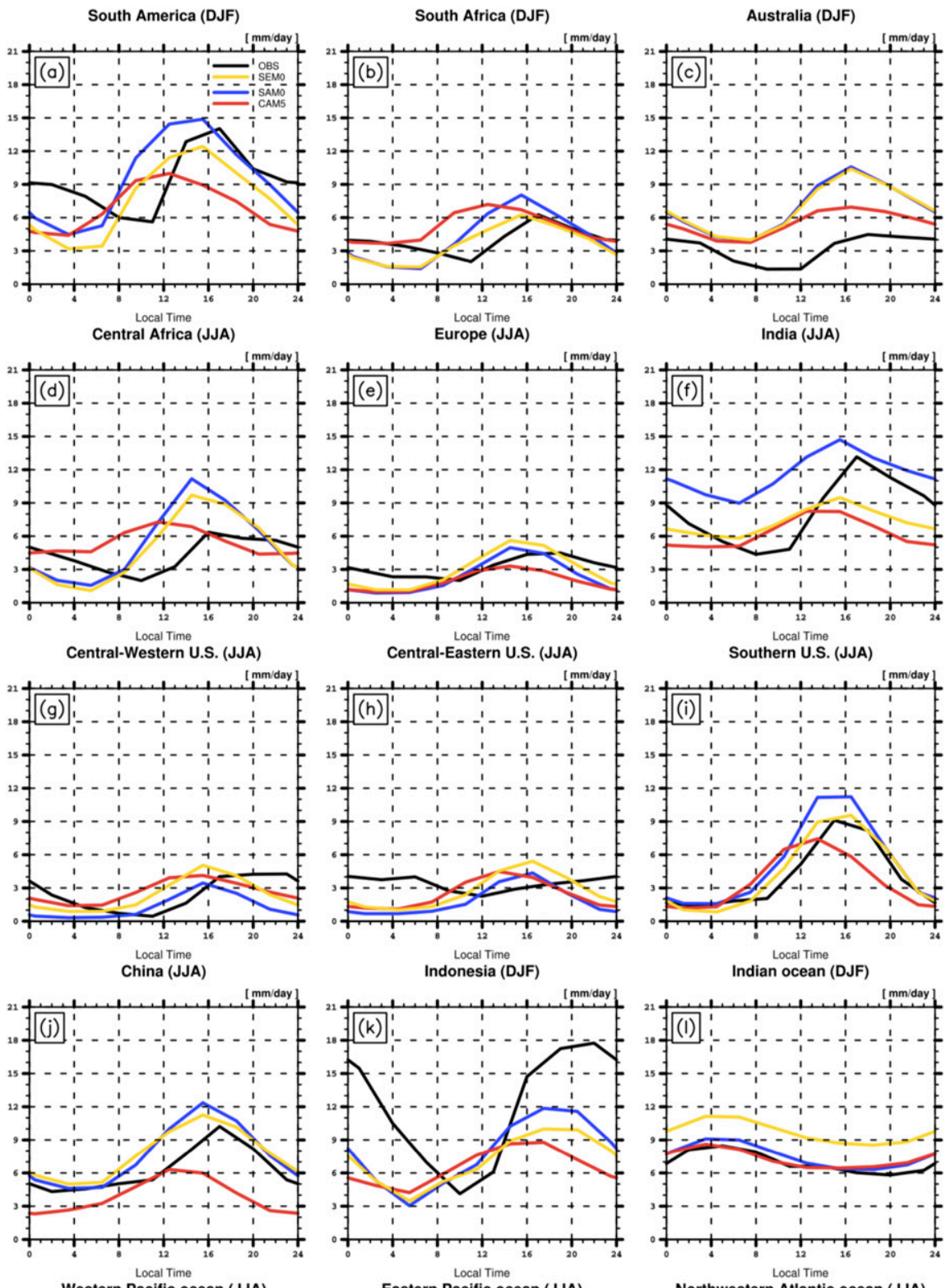

Western Pacific ocean (JJA)

Eastern Pacific ocean (JJA)

Northwestern Atlantic ocean (JJA)
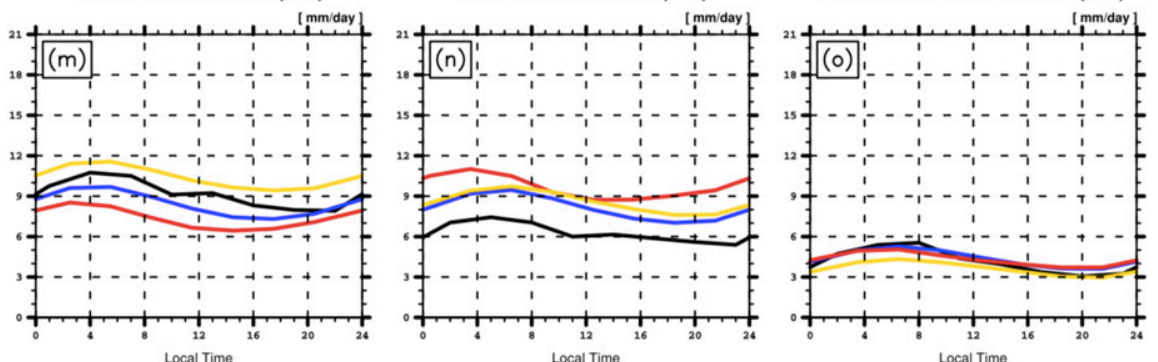

FIG. 17. The diurnal cycle of the total precipitation rate at the surface averaged over the following regions denoted in Fig. 16: (a) South America $\left(5^{\circ}-15^{\circ} \mathrm{S}, 60^{\circ}-45^{\circ} \mathrm{W}\right)$ during DJF, (b) South Africa $\left(7.5^{\circ}-15^{\circ} \mathrm{S}, 15^{\circ}-30^{\circ} \mathrm{E}\right)$ during DJF, (c) Australia $\left(17.5^{\circ}-25^{\circ} \mathrm{S}, 125^{\circ}-145^{\circ} \mathrm{E}\right)$ during $\mathrm{DJF}$, (d) central Africa $\left(5^{\circ}-15^{\circ} \mathrm{N}, 15^{\circ}-30^{\circ} \mathrm{E}\right)$ during JJA, (e) Europe $\left(45^{\circ}-50^{\circ} \mathrm{N}, 5^{\circ}-25^{\circ} \mathrm{E}\right)$ during JJA, (f) India $\left(20^{\circ}-25^{\circ} \mathrm{N}, 75^{\circ}-85^{\circ} \mathrm{E}\right)$ during JJA, (g) central-western United States $\left(35^{\circ}-40^{\circ} \mathrm{N}\right.$, 
SAM0, and CAM5 during DJF and JJA. Following Yang and Slingo (2001), a Fourier analysis is performed on surface precipitation to compute the amplitude, phase, and the percentage variance explained by the first harmonic function with a period of $24 \mathrm{~h}$ (i.e., diurnal cycle). In each figure, different colors denote the local hour with maximum surface precipitation fitted to the first harmonic, and darker shading denotes a larger amplitude of the diurnal cycle. It is not shown here, but the coupled simulations (SEM0, CESM1) produced diurnal cycles similar to the uncoupled simulations. SAM0 does a quite good job in reproducing the observed diurnal cycle of surface precipitation with maximum precipitation in the late afternoon (green color) over the summer continents, including the tropical maritime continents and in the early morning over the ocean (purple color), which is an improvement over CAM5 that produces maximum precipitation too early over the land. In the vicinity of large mountain areas, such as the Himalayas and the Andes, both SAM0 and CAM5 tend to capture the observed very early precipitation maximum even at this $1^{\circ}$ lat $\times 1^{\circ}$ lon horizontal resolution. However, similar to CAM5, SAM0 still fails to simulate the nocturnal maxima of surface precipitation over the central United States during JJA. This is an unexpected result, since SAM0 is designed to advect several subgrid variables associated with mesoscale convective organization (e.g., convective organization $\Omega$ representing the cold pool area and the associated perturbations of vertical velocity and thermodynamic scalars in the upflow branch of the mesoscale organized flow within the PBL) to mimic the observed propagation of mesoscale convective system and associated nocturnal maxima of surface precipitation rate. More research is necessary to understand this feature.

Figure 17 shows the diurnal time series of precipitation rate at the surface over several selected regions denoted in Figs. 16a and 16b. As shown, SAM0 does better job than CAM5 in reproducing the observed diurnal cycle over most of the summer continents (e.g., South America, South Africa, and central
Africa). However, both models fail to capture the observed nocturnal precipitation maxima over the United States during summer (Fig. 17h), and the timing of precipitation minima over the continents in both models is somewhat earlier than the observations. Over the maritime continents, the simulated diurnal amplitudes are smaller than that of the observations (Fig. 17k). In general, the diurnal amplitude of the observed precipitation over the ocean is smaller than that over the continents, which is correctly captured by the models. Over both the ocean and land, the diurnal cycle of coupled simulation (SEM0) is quite similar to that of uncoupled simulation (SAM0).

\section{4) TropicAl CyClone}

Figure 18 shows the annual mean track and passage FQ of tropical cyclones (TCs). Following previous studies (e.g., Hodges et al. 2003; Bengtsson et al. 2006), a tropical cyclone is identified using the 6-hourly instantaneous output if the relative vorticity at $850 \mathrm{hPa}$, $\xi_{850}$ is larger than $12.5 \times 10^{-5} \mathrm{~s}^{-1}\left(20 \times 10^{-5}\right.$ for the $0.5^{\circ}$ simulations), the warm-core strength, $\xi_{850}-\xi_{250}$ is larger than $12.5 \times 10^{-5} \mathrm{~s}^{-1}\left(20 \times 10^{-5}\right.$ for the $0.5^{\circ}$ simulations), and the two conditions are satisfied at least for two consecutive days. SAM0/SEM0 perform much better than CAM5/CESM1, which substantially underestimate the observation at the $1^{\circ}$ lat $\times 1^{\circ}$ lon resolution and simulates unrealistic TCs near the equator. In general, the number of simulated TC increases as the grid resolution becomes finer. Among the six simulations, SAM0 at the $0.5^{\circ}$ lat $\times 0.5^{\circ}$ lon resolution simulates the most realistic TC (Fig. 18k). However, similar to the other simulations, the passage FQ over the western Pacific and North Atlantic Oceans is still lower than the observations (Fig. 181); the tracks in the SPCZ are unrealistically extended southeastward; and spurious TCs are simulated over the South Atlantic Ocean.

Figure 19 shows the annual cycle of the genesis FQ of tropical cyclones averaged over several regions denoted in Figs. 18a and 18b. Over the western Pacific Ocean, the observed TCs are most frequently generated during late summer and early fall. Although underestimating the

$\left.105^{\circ}-97.5^{\circ} \mathrm{W}\right)$ during JJA, (h) central-eastern United States $\left(35^{\circ}-40^{\circ} \mathrm{N}, 97.5^{\circ}-90^{\circ} \mathrm{W}\right)$ during JJA, (i) southern United States $\left(30^{\circ}-35^{\circ} \mathrm{N}, 90^{\circ}-82.5^{\circ} \mathrm{W}\right)$ during JJA, (j) China $\left(25^{\circ}-30^{\circ} \mathrm{N}, 110^{\circ}-120^{\circ} \mathrm{E}\right)$ during JJA, (k) Indonesia $\left(2.5^{\circ} \mathrm{S}-2.5^{\circ} \mathrm{N}, 110^{\circ}-115^{\circ} \mathrm{E}\right)$ during DJF, (l) Indian Ocean $\left(15^{\circ} \mathrm{S}-0^{\circ}, 60^{\circ}-\right.$ $\left.80^{\circ} \mathrm{E}\right)$ during DJF, $(\mathrm{m})$ western Pacific Ocean $\left(5^{\circ}-15^{\circ} \mathrm{N}, 135^{\circ}-150^{\circ} \mathrm{E}\right)$ during JJA, (n) eastern Pacific Ocean $\left(2.5^{\circ}-10^{\circ} \mathrm{N}, 160^{\circ}-140^{\circ} \mathrm{W}\right)$ during JJA, (o) northwestern Atlantic Ocean $\left(35^{\circ}-42.5^{\circ} \mathrm{N}, 65^{\circ}-50^{\circ} \mathrm{W}\right)$ during JJA from the TRMM satellite observations, SEM0, SAM0, and CAM5. 


\section{Track}

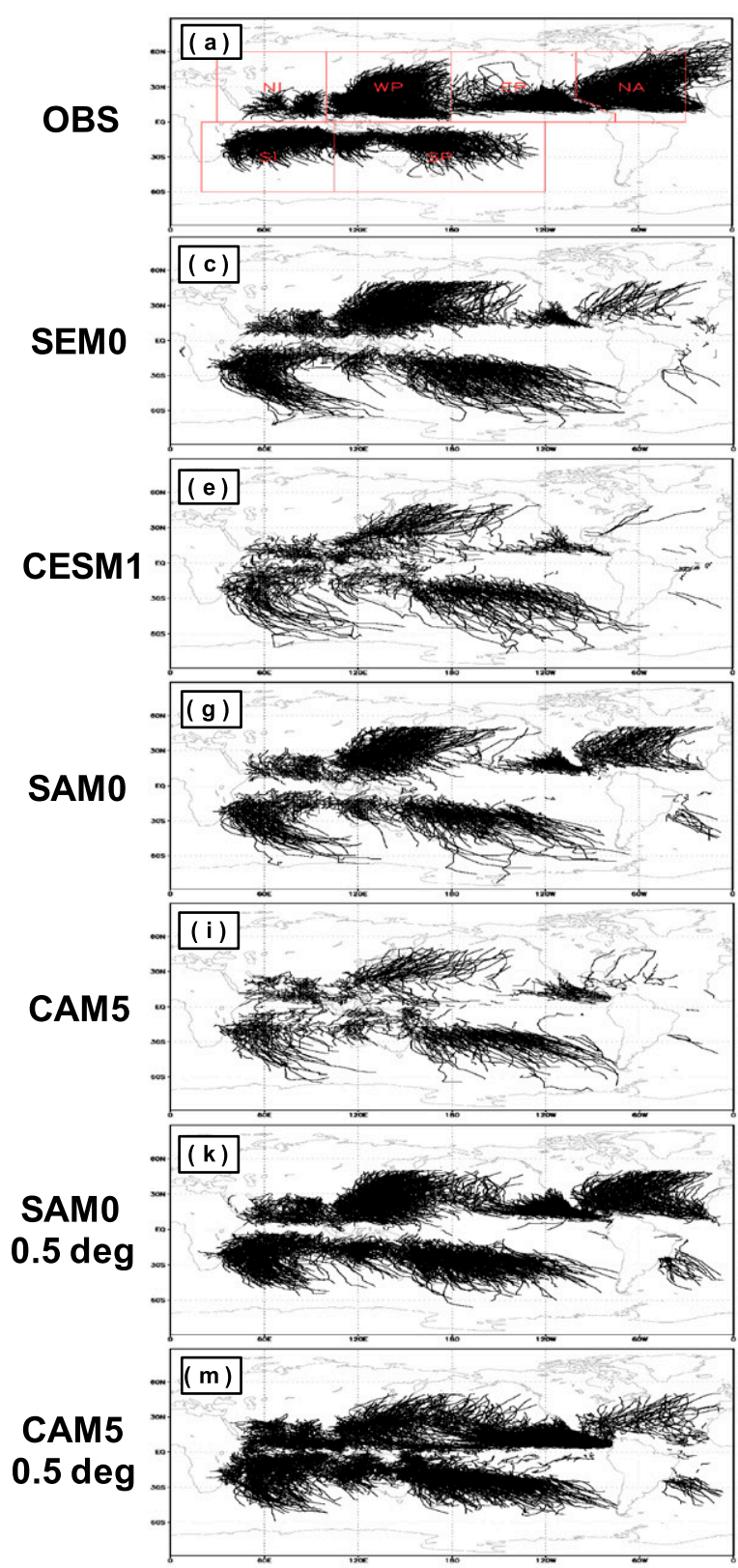

Passage Frequency
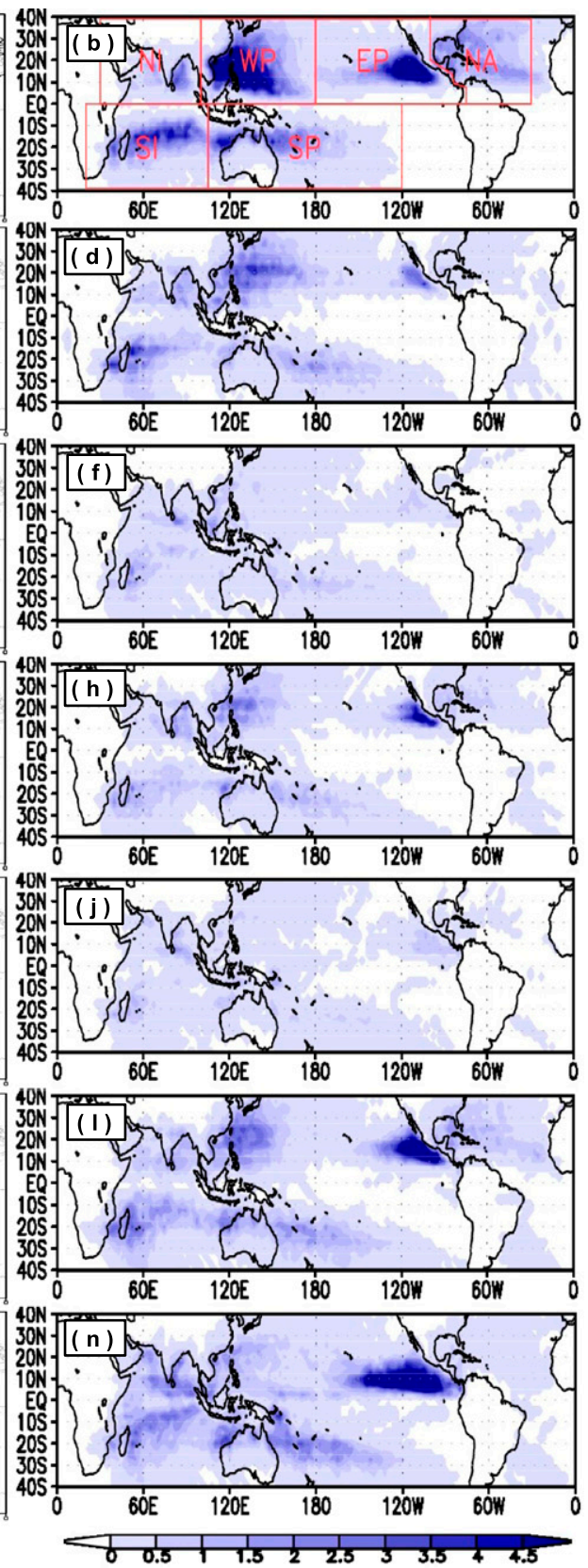

$[\# / \operatorname{grid}(2.5 \times 2.5) / \mathrm{yr}]$

FIG. 18. The annual-mean (left) track and (right) passage frequency of tropical cyclones from (a),(b) the JTWC observations (Chu et al. 2002) during January 1979-December 2014; (c),(d) SEM0; (e),(f) CESM1; (g),(h) SAM0; (i),(j) CAM5; (k),(l) SAM0 at the $0.5^{\circ}$ lat $\times 0.5^{\circ}$ lon horizontal resolution; and (m),(n) CAM5 at the $0.5^{\circ}$ lat $\times 0.5^{\circ}$ lon horizontal resolution during the same period. Using the 6-hourly instantaneous output, a tropical cyclone is identified if the relative vorticity at $850 \mathrm{hPa}, \xi_{850}$ is larger than $12.5 \times 10^{-5} \mathrm{~s}^{-1}\left(20 \times 10^{-5}\right.$ for the $0.5^{\circ}$ simulations $)$ and the warm-core strength, $\xi_{850}-\xi_{250}>12.5 \times 10^{-5} \mathrm{~s}^{-1}\left(20 \times 10^{-5}\right.$ for the $0.5^{\circ}$ simulations $)$ and the two conditions are satisfied at least for two consecutive days. 

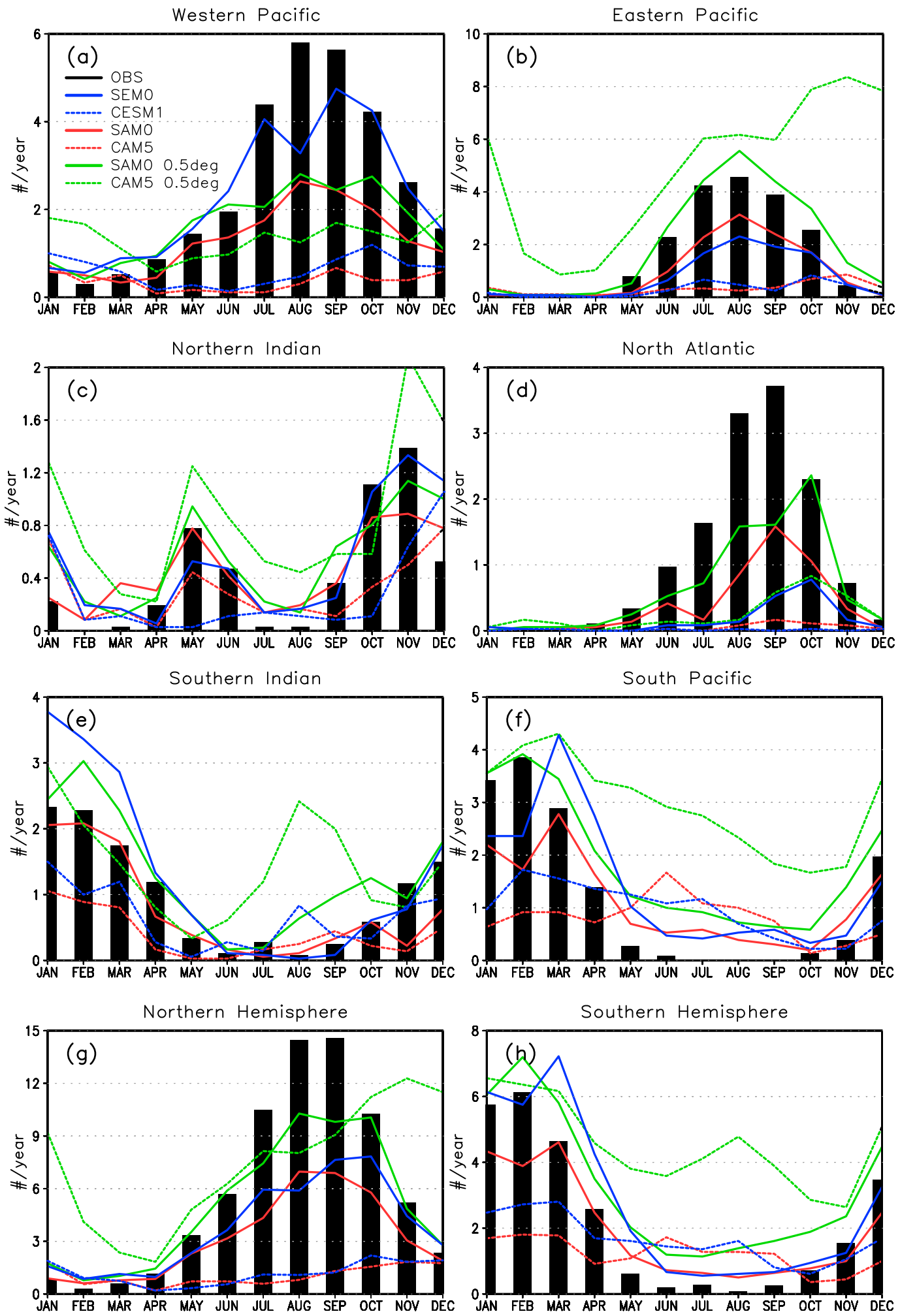

FIG. 19. The annual-cycle of the genesis frequency of tropical cyclones averaged over several regions denoted in Fig. 18 obtained from the JTWC observations (bar) and various simulations (lines). 
maximum number of occurrences, SAM0/SEM0 successfully reproduces the observed annual cycle, which is a substantial improvement over CAM5/CESM1 that tends to simulate maximum tropical cyclones during winter when the observation is a minimum. The superior performance of SAM0/SEM0 over CAM5/CESM1 can be seen in the other regions as well. Similar to the passage FQ, the genesis FQ of simulated TC increases as the model horizontal resolution becomes finer, but CAM5 shows a much stronger resolution sensitivity than SAM0, implying that SAM0 is more scale adaptive than CAM5. In contrast to the resolution, coupling with the interactive ocean exerts different impacts on the simulated tropical cyclone depending on the region: over the western Pacific Ocean, the genesis FQ increases substantially from SAM0 to SEM0, while the opposite is true over the eastern Pacific and North Atlantic Oceans. At the $0.5^{\circ}$ lat $\times 0.5^{\circ}$ lon resolution, CAM5-simulated annual-mean genesis FQ is comparable to that of the observations; however, the corresponding annual cycle is unrealistic with too much FQ during boreal winter in both hemispheres (Figs. 19g,h).

\section{5) AEROSOl DIRECT AND INDIRECT EFFECTS}

Figure 20 shows the differences in AOD, clear-sky net incoming $\mathrm{SW}$ and $\mathrm{LW}$ radiations at TOA [i.e., aerosol direct effect (ADE)], SWCF and LWCF at TOA [i.e., first aerosol indirect effect (AIE)], and PRECT at the surface (i.e., second AIE) between two experiments with the present-day (PD) and preindustrial (PI) aerosol emissions simulated by SAM0 and CAM5, respectively. The 30-yr climatology from the standalone simulations were used for these plots. In contrast to stratiform precipitation, aerosols in SAM0 and CAM5 do not control the production of convective precipitation, such that both models have some limitations in simulating true AIEs.

Global mean $\triangle \mathrm{AOD}$ between PD and PI is 0.018 for SAM0 and 0.014 for CAM5, and they are mostly concentrated in the Northern Hemisphere with the largest increases over China, equatorial western Africa, Europe, and South America. In both models, the whole climate system is cooled by ADE and the first AIE. Global mean ADE simulated by SAM0 $\left(-0.29 \mathrm{~W} \mathrm{~m}^{-2}\right)$ is slightly stronger than that of CAM5 $\left(-0.20 \mathrm{~W} \mathrm{~m}^{-2}\right)$ but global mean first AIE simulated by SAM0 $\left(-0.94 \mathrm{~W} \mathrm{~m}^{-2}\right)$ is slightly weaker than that of CAM5 $\left(-1.10 \mathrm{~W} \mathrm{~m}^{-2}\right)$. As a result, the ratio of the first AIE to ADE decreases from 5.5 in CAM5 to 3.2 in SAM0. Except for the Arctic area, the regions with a strong SW ADE cooling are roughly coincident with the areas with a large $\triangle$ AOD. The net aerosol effect on the global radiation budget at the model top is $-1.23 \mathrm{~W} \mathrm{~m}^{-2}$ for SAM0 and $-1.30 \mathrm{~W} \mathrm{~m}^{-2}$ for CAM5. It is interesting to note that the magnitudes of the individual SW AIE and LW AIE are substantially reduced from CAM5 (-1.645/0.542 for SW AIE and LW AIE, respectively) to SAM0 (-1.083/0.143) due mainly to the strong suppression of AIE over the southern and eastern oceans in Asia. In response to greater aerosol emissions, global mean PRECT decreases in both models but slightly more in SAM0, which, from the corresponding reduction of aerosol wet deposition, seems to explain why SAM0 has larger $\triangle$ AOD than does CAM5.

\section{Summary and conclusions}

Based on the Community Atmosphere Model version 5 (CAM5), the authors developed an atmospheric GCM, the Seoul National University Atmosphere Model version 0 with a Unified Convection Scheme (SAM0-UNICON), which replaces CAM5's shallow and deep convection schemes and revises CAM5's cloud macrophysics by diagnosing additional detrained cumulus fraction. As a contribution to CMIP6, we ran the mandatory five DECK simulations at a horizontal resolution of $0.98^{\circ}$ lat $\times 1.258^{\circ}$ lon with 30 vertical layers: a preindustrial coupled simulation for 500 years, an instantaneous 4 times increase of global $\mathrm{CO}_{2}$ concentration from the preindustrial coupled simulation for 150 years, a gradual increase of global $\mathrm{CO}_{2}$ concentration at the rate of $1 \% \mathrm{yr}^{-1}$ from the preindustrial coupled simulation for 150 years, a twentieth-century coupled simulation for 165 years from January 1850 to December 2014, and an AMIP simulation for 36 years from January 1979 to December 2014. The simulation results were compared with those of CAM5/CESM1 and observations. The AMIP and any coupled simulations with SAM0UNICON are simply referred as SAM0 and SEM0 (SNU Earth System Model version 0), respectively, and those with CAM5/CESM1 are referred as CAM5 and CESM1. Because the main difference between SAM0/SEM0 and CAM5/CESM1 is in the convection scheme, the changes of the simulated mean climate and variability from CAM5/CESM1 to SAM0/SEM0 can be understood as the sensitivity of global climate to convection processes. From the analysis of additional ensemble simulations of the twentieth-century and the instantaneous 4 times $\mathrm{CO}_{2}$ increase experiments, we checked that our analysis results shown in this study are not sensitive to random internal variabilities within the model.

Compared to CESM1, the SEM0 preindustrial simulation asymptotes to a well-defined stable equilibrium 
SAMO ( P.D. - P.I. )

$\triangle A O D$

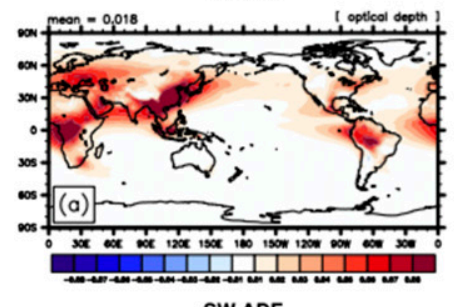

SW ADE

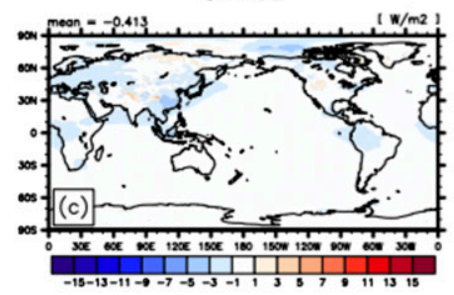

LW ADE

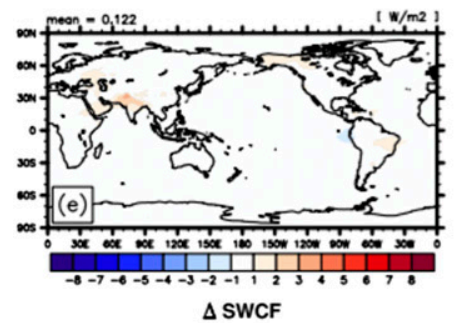

$\triangle$ SWCF

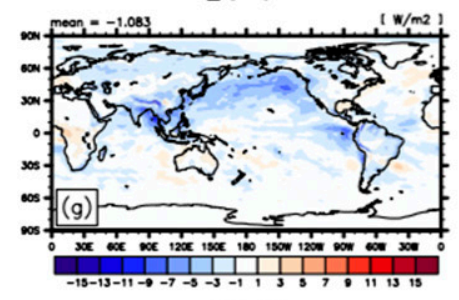

$\triangle$ LWCF

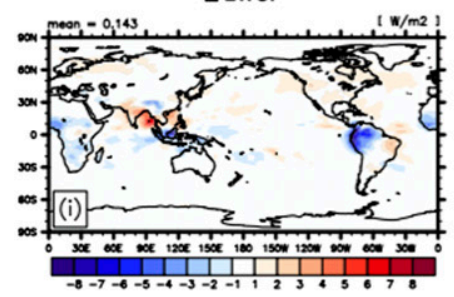

$\triangle$ PRECT

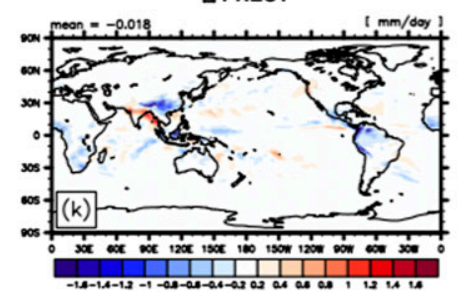

CAM5 ( P.D. - P.I. )

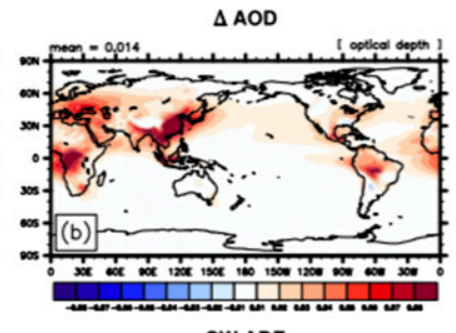

SW ADE

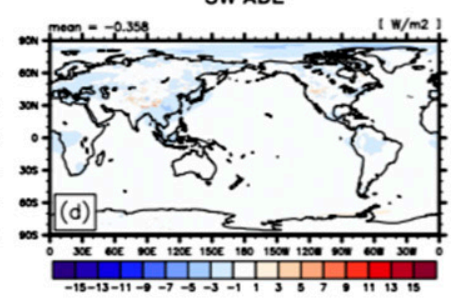

LW ADE

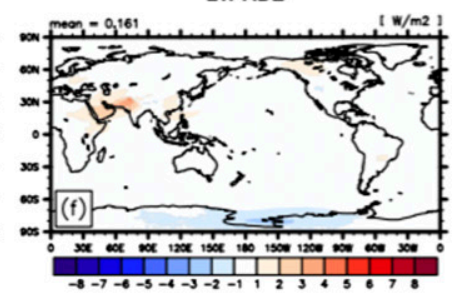

$\triangle$ SWCF

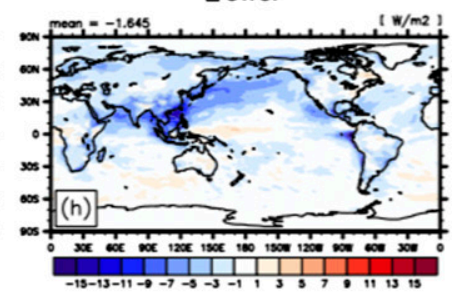

$\triangle$ LWCF

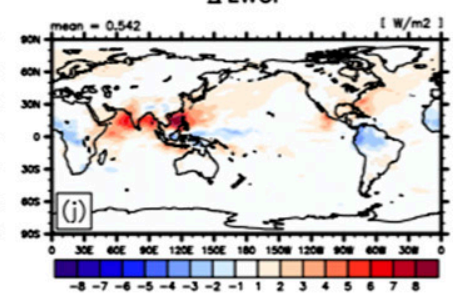

$\triangle$ PRECT

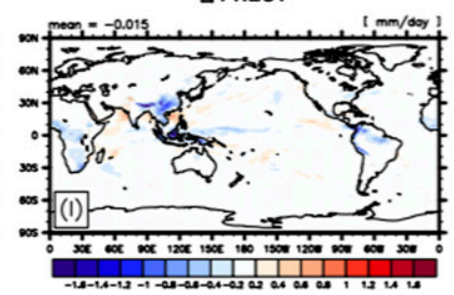

FIG. 20. The difference of (a),(b) AOD; (c),(d) clear-sky net downward SW radiation at TOA; (e),(f) clear-sky net downward $\mathrm{LW}$ radiation at TOA; (g),(h) SWCF at TOA; (i),(j) LWCF at TOA; and (k),(l) PRECT between two standalone simulations for 30 years with the PD aerosol emission and PI aerosol emission (PD - PI) with (left) SAM0 and (right) CAM5. Except for the aerosol emission, all the other external forcings and boundary conditions are set to those of the PD in the standalone simulations. 
state for global mean surface temperature (TS). After 50 years from the instantaneous 4 times increase of global $\mathrm{CO}_{2}$ concentration, both SEM0 and CESM1 reach an unstable equilibrium state with global mean TS about $4.7^{\circ}$ (SEM0) and $4.9^{\circ} \mathrm{C}$ (CESM1) warmer than the initial state. When the $\mathrm{CO}_{2}$ concentration gradually increases, global mean TS increases almost linearly with time. In the twentieth-century coupled simulation, both SEM0 and CESM1 successfully reproduce the observed rapid global warming after 1970 but the global mean TS averaged over 1971-2000 from SEM0 is about $0.6^{\circ} \mathrm{C}$ higher than that of CESM1. Global mean climate simulated by SAM0/SEM0 is roughly similar to that of CAM5/CESM1, but SAM0 (CESM1) performs slightly better than CAM5 (SEM0) in reproducing the observed global mean climate. Compared to CAM5/CESM1, SAM0/SEM0 improves the simulations of SWCF over the tropical deep convection and subtropical marine trade cumulus regimes, land rainfall, near-surface air temperature $T_{2 \mathrm{~m}}$ (and many of the remaining biases of $T_{2 \mathrm{~m}}$ seem to be associated with the biases in large-scale atmospheric flows and associated cloud and precipitation processes), AOD over the tropical deep convection and subtropical trade cumulus regions including SH oceans (however, both models still simulate too small AOD over the continents and large AOD over the SH oceans), sea ice fraction, and SST. Very interestingly, strong positive biases of $T_{2 \mathrm{~m}}$ over the central United States during JJA in the uncoupled simulation are substantially reduced by the coupling with the ocean. One of notable improvements from CESM1 to SEM0 is the suppression of a spurious double ITCZ over the eastern equatorial Pacific and Atlantic Oceans during DJF. In contrast, SEM0 provides poorer simulations of relative humidity, Pacific surface wind stress, and ocean rainfall.

SEM0 (and also CESM1 to a lesser degree) produces negative SLP biases over the tropical Pacific and Indian Oceans with a set of horseshoe-patterned SLP biases in the central-western tropical Pacific, particularly during DJF. These biases are accompanied by anomalous easterly surface wind along the equator that diverges into the nearby off-equatorial areas, cold SST presumably driven by equatorial Ekman upwelling, a dry bias in the equatorial troposphere with anomalously strong subsidence and easterly (westerly) wind in the lower (upper) equatorial troposphere, a too weak PRECT along the equator but strong PRECT along the ITCZ and SPCZ, and anomalously weak (strong) SWCF and LWCF along the equator (off-equatorial areas along the ITCZ and SPCZ). Some of the overestimated frequency of strong daily PRECT over
$200 \mathrm{~mm} \mathrm{day}^{-1}$ in SAM0/SEM0 is associated with anomalously strong precipitation in the ITCZ and SPCZ. Because complex feedback interactions are occurring between the gridscale atmospheric flows and subgrid cloud and precipitation processes and also between the atmosphere and ocean, it is not easy to determine the sources generating these biases. To the first order, these biases are likely due to the errors in the horizontal and vertical distribution of latent heating from the convection scheme that interact strongly with the circulation and lead to unrealistic rainfall and flow patterns. Additional plausible hypotheses explaining these biases are 1) too weak convective momentum transport in SEM0, which induces anomalous easterly surface wind and cold SST along the equator and associated high SLP through the hydrostatic adjustment of the atmosphere to underlying cold SST, and the resulting biases of atmospheric flows, cloud, and precipitation processes, and 2) the absence of condensate loading effects on atmospheric pressure. In SEM0 (also CESM1), the dynamic core does not take into account the contribution of cloud and precipitation condensates in the computation of atmospheric pressure at the model interfaces, such that SLP in the area with heavy precipitation and clouds (e.g., ITCZ and SPCZ) may be underestimated, resulting in anomalous surface flow converging into ITCZ and SPCZ. A set of sensitivity simulations is planned to test these hypotheses.

During the present-day period, both SEM0 and CESM1 produce a sea ice fraction that is too high along the Arctic periphery at $75^{\circ} \mathrm{N}$, including the Sea of Okhotsk and also in the SH circumpolar region. Based on the spatial coherency, some of the strong negative SST biases in the Labrador Sea and northwestern Pacific Ocean along $35^{\circ} \mathrm{N}$ and the positive and negative SST biases in the SH circumpolar region are speculated to be associated with the biases in the sea ice fraction. Through a hydrostatic adjustment, the negative SST biases in the northwestern Pacific Ocean during JJA may enhance anomalous high SLP there, which in turn can further cool the underlying SST by promoting the formation of marine stratocumulus that reflects incoming SW radiation. SEM0 simulates a zonally symmetric positive SLP bias along $45^{\circ}-50^{\circ} \mathrm{S}$ during DJF, which is responsible for the zonally symmetric positive biases of surface wind stress along $30^{\circ}$ and $60^{\circ} \mathrm{S}$ and the westerly wind biases centered at $60^{\circ} \mathrm{S}$ in the entire troposphere. It is speculated that some of these biases in SLP and wind in the SH circumpolar region during DJF are also associated with the biases in sea ice fraction. Anomalously strong upward heat flux at the surface and the oceanic Ekman 
transport driven by strong westerly surface wind may contribute to the positive biases in the sea ice fraction here. In turn, a greater sea ice fraction in the SH circumpolar region may enhance the tropospheric westerly wind by strengthening the meridional temperature gradient across the boundary of the enhanced sea ice fraction and the associated midlatitude jet stream. More studies are planned to test this hypothesis on the relationship among the biases of sea ice fraction, SST, SLP, wind, and marine stratocumulus.

Similar to CESM1, SEM0 successfully reproduces the observed ENSO with reasonable simulations of the observed power peak of the Niño-3.4 SST anomalies at a period of 4-7 years, the annual cycle of the monthly standard deviation of Niño-3.4 SST anomalies, time evolution of equatorial SST anomalies during El Niño/ La Niña events, and global teleconnection patterns of SLP and TS associated with the El Niño. Compared to CAM5/CESM1, SAM0/SEM0 much better simulates various aspects of the observed Madden-Julian oscillation as well as the Kelvin and Rossby waves. However, the simulated eastward propagation signals of PRECT and OLR across $150^{\circ} \mathrm{E}$ are substantially weaker than the observations during winter, presumably due in part to the dry bias in the simulated mean climate over the central equatorial Pacific Ocean. SAM0 does a good job of reproducing the observed diurnal cycle of surface precipitation with the maximum precipitation in the late afternoon over the summer continents and in the early morning over the ocean, which is an improvement over CAM5 that produces the maximum precipitation too early over land. However, similar to CAM5, SAM0 fails to simulate the observed nocturnal maxima of surface precipitation in the central and eastern United States during JJA. In terms of simulating tropical cyclones (TC), SAM0/ SEM0 performs much better than CAM5/CESM1, which substantially underestimates the observed TC genesis at the $1^{\circ}$ lat $\times 1^{\circ}$ lon horizontal resolution, generates unrealistic TC near the equator, and simulates the maximum TC genesis frequency during winter when the observation is a minimum. At the $0.5^{\circ}$ lat $\times 0.5^{\circ}$ lon horizontal resolution, SAM0 reproduces the observed annual cycle of tropical cyclones well over the globe, but the TC genesis frequency over the western Pacific and North Atlantic oceans during active seasons is still lower than the observations. The global mean aerosol direct effect (ADE) simulated by SAM0 $\left(-0.3 \mathrm{~W} \mathrm{~m}^{-2}\right)$ is slightly stronger than CAM5 $(-0.2)$, the global mean aerosol indirect effect (AIE) simulated by SAM0 $(-0.94)$ is slightly weaker than CAM5 $(-1.1)$, and the global mean PRECT decreases slightly from the preindustrial to present-day aerosol emission simulations in both models. Notably, the magnitudes of individual SW.AIE/LW.AIE are substantially reduced from CAM5 $(-1.65 / 0.54)$ to SAM0 $(-1.1 / 0.14)$.

Using the CMIP6 simulations as a test bed, we showed that SAM0-UNICON is as good as CAM5/ CESM1 in reproducing the observed global mean climate and ENSO. This is a very encouraging result, because in contrast to CAM5's shallow and deep convection schemes, UNICON is developed as a process-based model without relying on any equilibrium constraints (e.g., CIN or CAPE closures) that prevent the simulated mean state from deviating far from a certain equilibrium state. As well as the mean climate, SAM0-UNICON successfully simulates the observed variabilities that have been difficult to simulate in GCMs, the MJO, diurnal cycle of precipitation, and tropical cyclones, much better than CAM5/ CESM1, due to its capability to simulate various atmospheric convections (e.g., dry-moist, forced-free, and shallow-deep convection) in a seamless, consistent, and unified way with a minimum amount of empirical or ad hoc closures. Although more research is needed to improve SAM0-UNICON, a successful simulation of the observed ENSO, MJO, diurnal cycle of precipitation, tropical cyclones, and global warming with a decent mean climate will provide the community with unique opportunities to explore various interactions between these phenomena.

Aiming at simulating more realistic aerosol-cloudturbulence-precipitation-radiation interactions over a wide range of GCM grid sizes without a resolutiondependent tuning exercise, the authors are continuously working on the following 1) developing an integrated vertical overlap parameterization of cumulus and stratus and implementing it into all relevant physics parameterizations in a fully consistent way (e.g., UNICON, stratus microphysics, radiation, aerosol wet deposition and activation schemes), some of which have already been completed (Park 2017, 2018; Park et al. 2019); 2) incorporating stochastic components into UNICON in order to develop a scale-adaptive GCM; 3) imposing consistency on the treatment of cloud-borne and interstitial aerosols in all relevant physics parameterizations and advection scheme; and 4) implementing a double-moment cloud microphysics scheme into UNICON. These works will be reported in the near future.

Acknowledgments. We express our thanks to the precedent modelers who contributed to developing CAM5 on which our SAM0-UNICON is based. This work was supported by the Creative-Pioneering 
Researchers Program of Seoul National University (SNU; 3345-20180017).

\section{REFERENCES}

Abdul-Razzak, H., and S. J. Ghan, 2000: A parameterization of aerosol activation: 2. multiple aerosol types. J. Geophys. Res., 105, 6837-6844, https://doi.org/10.1029/1999JD901161.

Adler, R. F., and Coauthors, 2003: The version-2 Global Precipitation Climatology Project (GPCP) monthly precipitation analysis (1979-present). J. Hydrometeor., 4, 1147-1167, https://doi.org/10.1175/1525-7541(2003)004<1147: TVGPCP $>2.0 . \mathrm{CO} ; 2$.

Ahn, M.-S., D. Kim, S. Park, and Y.-G. Ham, 2019: Do we need to parameterize mesoscale convective organization to mitigate the MJO-mean state tradeoff? Geophys. Res. Lett., 46, 2293 2301, https://doi.org/10.1029/2018GL080314.

Bengtsson, L., K. I. Hodges, and E. Roeckner, 2006: Storm tracks and climate change. J. Climate, 19, 3518-3543, https://doi.org/ 10.1175/JCLI3815.1.

Bentamy, A., P. Queffeulou, Y. Quilfen, and K. Katsaros, 1999: Ocean surface wind fields estimated from satellite active and passive microwave instruments. IEEE Trans. Geosci. Remote Sens., 37, 2469-2486, https://doi.org/10.1109/36.789643.

Bretherton, C. S., and S. Park, 2009: A new moist turbulence parameterization in the community atmosphere model. J. Climate, 22, 3422-3448, https://doi.org/10.1175/2008JCLI2556.1.

Chu, J.-H., C. R. Sampson, A. S. Levine, and E. Fukada, 2002: The joint typhoon warning center tropical cyclone best-tracks, 1945-2000. Ref. NRL/MR/7540-02, 16 pp.

Eyring, V., S. Bony, G. A. Meehl, C. A. Senior, B. Stevens, R. J. Stouffer, and K. E. Taylor, 2016: Overview of the Coupled Model Intercomparison Project phase 6 (CMIP6) experimental design and organization. Geosci. Model Dev., 9, 1937-1958, https://doi.org/10.5194/gmd-9-1937-2016.

Hodges, K. I., B. J. Hoskins, J. Boyle, and C. Thorncroft, 2003: A comparison of recent reanalysis datasets using objective feature tracking: Storm tracks and tropical easterly waves. Mon. Wea. Rev., 131, 2012-2037, https://doi.org/10.1175/ 1520-0493(2003)131<2012:ACORRD>2.0.CO;2.

Huffman, G., and Coauthors, 2007: The TRMM Multisatellite Precipitation Analysis (TMPA): Quasi-global, multiyear, combined-sensor precipitation estimates at fine scales. J. Hydrometeor., 8, 38-55, https://doi.org/10.1175/JHM560.1.

Hurrell, J. W., and Coauthors, 2013: The Community Earth System Model: A framework for collaborative research. Bull. Amer. Meteor. Soc., 94, 1339-1360, https://doi.org/10.1175/BAMS-D-12-00121.1.

Iacono, M. J., J. Delamere, E. Mlawer, M. Shephard, S. Clough, and W. Collins, 2008: Radiative forcing by long-lived greenhouse gases: Calculations with the AER radiative transfer models. J. Geophys. Res., 113, D13103, https://doi.org/10.1029/2008JD009944.

Kalnay, E., and Coauthors, 1996: The NCEP/NCAR Reanalysis 40-Year Project. Bull. Amer. Meteor. Soc., 77, 437-471, https:// doi.org/10.1175/1520-0477(1996)077<0437:TNYRP>2.0.CO;2.

Kinne, S., and Coauthors, 2006: An AeroCom initial assessmentOptical properties in aerosol component modules of global models. Atmos. Chem. Phys., 6, https://doi.org/10.5194/ acp-6-1815-2006.

Liebmann, B., and C. A. Smith, 1996: Description of a complete (interpolated) outgoing longwave radiation dataset. Bull. Amer. Meteor. Soc., 77, 1275-1277, https://doi.org/10.1175/ 1520-0477-77.6.1274.
Lin, S.-J., and R. B. Rood, 1996: Multidimensional flux-form semi-lagrangian transport schemes. Mon. Wea. Rev., 124 (9), 2046-2070, https://doi.org/10.1175/1520-0493(1996)124<2046: MFFSLT $>2.0 . \mathrm{CO} ; 2$.

—, and - 1997: An explicit flux-form semi-Lagrangian shallow-water model on the sphere. Quart. J. Roy. Meteor. Soc., 123, 2477-2498, https://doi.org/10.1002/qj.49712354416.

Liu, X., and J. E. Penner, 2005: Ice nucleation parameterization for global models. Meteor. Z., 14, 499-514, https://doi.org/10.1127/ 0941-2948/2005/0059.

_ , and Coauthors, 2012: Toward a minimal representation of aerosols in climate models: Description and evaluation in the Community Atmosphere Model CAM5. Geosci. Model Dev., 5, 709-739, https://doi.org/10.5194/gmd-5-709-2012.

Loeb, N., B. Wielicki, D. Doelling, G. Smith, D. Keyes, S. Kato, N. Manalo-Smith, and T. Wong, 2009: Toward optimal closure of the earth's top-of-atmosphere radiation budget. J. Climate, 22, 748-766, https://doi.org/10.1175/2008JCLI2637.1.

Madden, R. A., and P. R. Julian, 1971: Detection of a 40-50 day oscillation in the zonal wind in the tropical Pacific. $J$. Atmos. Sci., 28, 702-708, https://doi.org/10.1175/15200469(1971)028<0702:DOADOI $>2.0$.CO;2.

Mitchell, D. L., 2002: Effective diameter in radiation transfer: General definition, applications, and limitations. J. Atmos. Sci., 59, 2330-2346, https://doi.org/10.1175/1520-0469(2002) $059<2330$ :EDIRTG $>2.0$. CO;2.

Monin, A., and A. Obukhov, 1954: Basic laws of turbulent mixing in the surface layer of the atmosphere. Tr. Geofiz. Inst., Akad. Nauk SSSR, 24, 163-187.

Morrison, H., and A. Gettelman, 2008: A new two-moment bulk stratiform cloud microphysics scheme in the Community Atmosphere Model, version 3 (CAM3). Part I: Description and numerical tests. J. Climate, 21, 3642-3659, https://doi.org/ 10.1175/2008JCLI2105.1.

Neale, R. B., J. Richter, and M. Jochum, 2008: The impact of convection on ENSO: From a delayed oscillator to a series of events. J. Climate, 21, 5904-5924, https://doi.org/10.1175/2008JCLI2244.1. , and Coauthors, 2010: Description of the NCAR Community Atmosphere Model (CAM 4.0). NCAR Tech. Note NCAR/ TN-485+STR, 212 pp., www.cesm.ucar.edu/models/ccsm4.0/ cam/docs/description/cam4_desc.pdf.

Park, S., 2014a: A Unified Convection Scheme (UNICON). Part I: Formulation. J. Atmos. Sci., 71, 3902-3930, https://doi.org/ 10.1175/JAS-D-13-0233.1.

_- 2014b: A Unified Convection Scheme (UNICON). Part II: Simulation. J. Atmos. Sci., 71, 3931-3973, https://doi.org/ 10.1175/JAS-D-13-0234.1.

— 2017: A heuristic parameterization for the integrated vertical overlap of cumulus and stratus. J. Adv. Model. Earth Syst., 9, 24372465, https://doi.org/10.1002/2017MS001055.

_ 2018: An economical analytical equation for the integrated vertical overlap of cumulus and stratus. J. Adv. Model. Earth Syst., 10, 826-841, https://doi.org/10.1002/2017MS001190.

__ , and C. Bretherton, 2009: The University of Washington shallow convection and moist turbulence schemes and their impact on climate simulations with the community atmosphere model. J. Climate, 22, 3449-3469, https://doi.org/ 10.1175/2008JCLI2557.1.

,-- , and P. J. Rasch, 2014: Integrating cloud processes in the community atmosphere model, version 5. J. Climate, 27, 68216856, https://doi.org/10.1175/JCLI-D-14-00087.1.

— E.-H. Baek, B.-M. Kim, and S.-J. Kim, 2017: Impact of detrained cumulus on climate simulated by the Community 
Atmosphere Model version 5 with a unified convection scheme. J. Adv. Model. Earth Syst., 9, 1399-1411, https:// doi.org/10.1002/2016MS000877.

— - S. Kim, J. Shin, and E. Oh, 2019: Impact of integrated vertical overlap of cumulus and stratus on the global precipitation and radiation processes in the Seoul National University Atmosphere Model Version 0 with a Unified Convection Scheme (SAM0-UNICON). J. Adv. Model. Earth Syst., 11, 468-484, https://doi.org/10.1029/2018MS001570.

Phillips, A. S., C. Deser, and J. Fasullo, 2014: Evaluating modes of variability in climate models. Eos, Trans. Amer. Geophys. Union, 95, 453-455, https://doi.org/ 10.1002/2014EO490002.

Pincus, R., H. W. Barker, and J.-J. Morcrette, 2003: A fast, flexible, approximate technique for computing radiative transfer in inhomogeneous cloud fields. J. Geophys. Res., 108, 4376, https://doi.org/10.1029/2002JD003322.

Rayner, N., D. E. Parker, E. Horton, C. Folland, L. Alexander, D. Rowell, E. Kent, and A. Kaplan, 2003: Global analyses of sea surface temperature, sea ice, and night marine air temperature since the late nineteenth century. J. Geophys. Res., 108, 4407, https://doi.org/10.1029/2002JD002670.

Richter, J., and P. Rasch, 2008: Effects of convective momentum transport on the atmospheric circulation in the community atmosphere model, version 3. J. Climate, 21, 1487-1499, https://doi.org/10.1175/2007JCLI1789.1.

Simmons, A., S. Uppala, D. Dee, and S. Kobayashi, 2007: ERAInterim: New ECMWF reanalysis products from 1989 onwards. ECMWF Newsletter, No. 110, ECMWF, Reading, United Kingdom, 25-35, https://www.ecmwf.int/sites/ default/files/elibrary/2006/14615-newsletter-no110-winter200607.pdf.
Taylor, K. E., 2001: Summarizing multiple aspects of model performance in a single diagram. J. Geophys. Res., 106, 71837192, https://doi.org/10.1029/2000JD900719.

Teixeira, J., and Y.-J. Kim, 2008: On a simple parameterization of convective cloud fraction. Asia-Pac. J. Atmos. Sci, 44 (2), 191-199.

Tiedtke, M., 1993: Representation of clouds in large-scale models. Mon. Wea. Rev., 121, 3040-3061, https://doi.org/10.1175/15200493(1993) $121<3040:$ ROCILS $>2.0 . C O ; 2$.

Willmott, C. J., and K. Matsuura, 1995: Smart interpolation of annually averaged air temperature in the United States. J. Appl. Meteor., 34, 2577-2586, https://doi.org/10.1175/ 1520-0450(1995)034<2577:SIOAAA >2.0.CO;2.

Yang, G.-Y., and J. Slingo, 2001: The diurnal cycle in the tropics. Mon. Wea. Rev., 129, 784-801, https://doi.org/ 10.1175/1520-0493(2001)129<0784:TDCITT>2.0.CO;2.

Yoo, C., S. Park, D. Kim, J.-H. Yoon, and H.-M. Kim, 2015: Boreal winter MJO teleconnection in the Community Atmosphere Model version 5 with the unified convection parameterization. J. Climate, 28, 8135-8150, https://doi.org/ 10.1175/JCLI-D-15-0022.1.

Zhang, G. J., and N. A. McFarlane, 1995: Sensitivity of climate simulations to the parameterization of cumulus convection in the $\mathrm{Ca}-$ nadian Climate Centre general circulation model. Atmos.-Ocean, 33, 407-446, https://doi.org/10.1080/07055900.1995.9649539.

Zhang, L., S. Gong, J. Padro, and L. Barrie, 2001: A sizesegregated particle dry deposition scheme for an atmospheric aerosol module. Atmos. Environ., 35, 549-560, https://doi.org/10.1016/S1352-2310(00)00326-5.

Zhang, M., W. Lin, C. Bretherton, J. Hack, and P. Rasch, 2003: A modified formulation of fractional stratiform condensation rate in the NCAR Community Atmospheric Model (CAM2). J. Geophys. Res., 108, 4035, https://doi.org/10.1029/2002JD002523. 